\title{
Functional implementation of a linear glycolysis for sugar catabolism in Pseudomonas putida
}

Sánchez-Pascuala, Alberto; Fernandez-Cabezon, Lorena; de Lorenzo, Víctor; Nikel, Pablo Ivan

Published in:

Metabolic Engineering

Link to article, DOI:

10.1016/j.ymben.2019.04.005

Publication date:

2019

Document Version

Peer reviewed version

Link back to DTU Orbit

Citation (APA):

Sánchez-Pascuala, A., Fernandez-Cabezon, L., de Lorenzo, V., \& Nikel, P. I. (2019). Functional implementation of a linear glycolysis for sugar catabolism in Pseudomonas putida. Metabolic Engineering, 54, 200-211. https://doi.org/10.1016/j.ymben.2019.04.005

\section{General rights}

Copyright and moral rights for the publications made accessible in the public portal are retained by the authors and/or other copyright owners and it is a condition of accessing publications that users recognise and abide by the legal requirements associated with these rights.

- Users may download and print one copy of any publication from the public portal for the purpose of private study or research.

- You may not further distribute the material or use it for any profit-making activity or commercial gain

- You may freely distribute the URL identifying the publication in the public portal 


\section{Functional implementation of a linear glycolysis for sugar catabolism in}

Pseudomonas putida

by

Alberto Sánchez-Pascualaa1, Lorena Fernández-Cabezón ${ }^{b}$, Víctor de Lorenzoa*, and Pablo I. Nikelb*

a Systems and Synthetic Biology Program, Centro Nacional de Biotecnología (CNB-CSIC), Campus de Cantoblanco, 28049 Madrid, Spain

b The Novo Nordisk Foundation Center for Biosustainability, Technical University of Denmark, 2800 Kongens Lyngby, Denmark

${ }^{1}$ Current address: The Max Planck Institute for Terrestrial Microbiology; Karl-von-FrischStraße 10, 35043 Marburg, Germany

Keywords: Pseudomonas putida, glycolysis, metabolic engineering, glucose, synthetic metabolism, synthetic biology

Running title: $\quad$ Engineering linear glycolysis in Pseudomonas putida

* Correspondence to: Víctor de Lorenzo (vdlorenzo@cnb.csic.es)

Centro Nacional de Biotecnología (CNB-CSIC)

Madrid, Spain

Tel: (+34 91) 5854573

Pablo I. Nikel (pabnik@biosustain.dtu.dk)

The Novo Nordisk Foundation Center for Biosustainability, Technical University of Denmark

Lyngby, Denmark

Tel: (+45 93) 511918 
3 The core metabolism for glucose assimilation of the soil bacterium and platform strain 4 Pseudomonas putida KT2440 has been reshaped from the native, cyclically-operating Entner5 Doudoroff (ED) pathway to a linear Embden-Meyerhof-Parnas (EMP) glycolysis. The genetic 6 strategy deployed to obtain a suitable host for the synthetic EMP route involved not only 7 eliminating enzymatic activities of the ED pathway, but also erasing peripheral reactions for 8 glucose oxidation that divert carbon skeletons into the formation of organic acids in the periplasm.

9 Heterologous glycolytic enzymes, recruited from Escherichia coli, were genetically knocked-in in 10 the mutant strain to fill the metabolic gaps for the complete metabolism of glucose to pyruvate 11 through a synthetic EMP route. A suite of genetic, physiological, and biochemical tests in the 12 thereby-refactored $P$. putida strain-which grew on glucose as the sole carbon and energy 13 source-demonstrated the functional replacement of the native sugar metabolism by a synthetic 14 catabolism. ${ }^{13}$ C-labelling experiments indicated that the bulk of pyruvate in the resulting strain 15 was generated through the metabolic device grafted in $P$. putida. Strains carrying the synthetic 16 glycolysis were further engineered for carotenoid synthesis from glucose, indicating that the 17 implanted EMP route enabled higher carotenoid content on biomass and yield on sugar as 18 compared with strains running the native hexose catabolism. Taken together, our results highlight 19 how conserved metabolic features in a platform bacterium can be rationally reshaped for 20 enhancing physiological traits of interest. 
3 Because of its naturally-evolved metabolic and stress-tolerant qualities, Pseudomonas putida 4 KT2440 constitutes a prime example of an environmental bacterium that has been established as an attractive host for biotechnological applications (Belda et al., 2016; Calero and Nikel, 2019; Nelson et al., 2002; Nikel and de Lorenzo, 2018). Among other reasons, this occurrence stems 
1 The absence of a functional EMP pathway in strain KT2440 can be traced to the lack of the key

2 glycolytic 6-phosphofructo-1-kinase (Pfk) activity. However, the addition of the PfkA enzyme from

3 Escherichia coli K-12 into the biochemical network of $P$. putida did not suffice to activate an EMP

4 route for glucose consumption (Chavarría et al., 2013), even when the ED pathway was

5 genetically blocked. The GlucoBrick platform, a set of standard glycolytic modules encoding all

6 the EMP enzymes from E. coli K-12 in a fixed format, has been thus designed as a tool for 7 engineering glycolysis in Gram-negative bacteria (Sánchez-Pascuala et al., 2017; 2018). The

8 GlucoBrick platform is composed by two modules, each of them consisting of five individual

9 bricks. Module I (GBI) encodes the enzymes of the preparatory phase, which uses ATP to 10 convert hexoses into trioses- $P$ [i.e. glucose $\rightarrow$ glyceraldehyde-3-P (GA3P)] (Fig. 1b). Module II 11 (GBII) encodes the enzymes of the pay-off phase, the second half of the EMP route, and it 12 converts trioses phosphate into pyruvate (Pyr) (i.e. GA3P $\rightarrow$ Pyr). With these portable metabolic 13 modules in hand-and the panoply of genetic tools available for editing the genome of $P$. putida 14 (Martínez-García and de Lorenzo, 2017; Wirth et al., 2019)—the present work explores the deep 15 metabolic refactorization of strain KT2440, in which the ED pathway (and the EDEMP cycle 16 thereof) is replaced by a rationally-designed, synthetic EMP glycolysis. Our results demonstrate 17 that the careful rewiring of native biochemical pathways and the genetic grafting of an artificial glycolysis device enables glucose-dependent growth of $P$. putida via a linear pathway for sugar catabolism. These developments not only open new possibilities of bacterial chassis engineering for creating novel whole-cell biocatalysts, but also rise interesting questions on how the core metabolism defines species identity.

\section{Materials and Methods}

\subsection{Bacterial strains, plasmids, and culture conditions}

The bacterial strains employed in this study are listed in Table 1. E. coli and P. putida cultures were incubated at $37^{\circ} \mathrm{C}$ and $30^{\circ} \mathrm{C}$, respectively. For propagation and construction of plasmids, $E$. coli strains CC118 and DH5 $\lambda$ pir were grown in lysogeny broth (LB) medium (Green and Sambrook, 2012; Martínez-García et al., 2017). For physiology experiments, and to obtain cellfree extracts to be used in enzyme activity assays, bacterial cells were grown with rotatory 
1 shaking at 170 r.p.m. in 250-ml Erlenmeyer flasks filled with $50 \mathrm{ml}$ of $\mathrm{M} 9$ minimal medium, 2 containing $6 \mathrm{~g} \mathrm{l}^{-1} \mathrm{Na}_{2} \mathrm{HPO}_{4}, 3 \mathrm{~g} \mathrm{l}^{-1} \mathrm{KH}_{2} \mathrm{PO}_{4}, 1.4 \mathrm{~g} \mathrm{l}^{-1}\left(\mathrm{NH}_{4}\right)_{2} \mathrm{SO}_{4}, 0.5 \mathrm{~g} \mathrm{l}^{-1} \mathrm{NaCl}$, and $0.2 \mathrm{~g} \mathrm{l}^{-1}$ $3 \mathrm{MgSO}_{4} \cdot 7 \mathrm{H}_{2} \mathrm{O}$ (Nikel and de Lorenzo, 2013b). Unless otherwise indicated, minimal medium 4 cultures were added with glucose at $20 \mathrm{mM}$ or succinate at $30 \mathrm{mM}$. The same concentration of 5 carbon atoms $(120 \mathrm{mM})$ was adopted when cultures were inoculated under either glycolytic 6 (glucose) or gluconeogenic (succinate) conditions. In order to adapt the cells to grow on glucose 7 from rich LB medium, pre-inocula were prepared with a few isolated colonies picked from LB 8 medium plates. Pre-inocula were grown overnight (ca. $12 \mathrm{~h}$, with the exception of engineered 9 strains with a low growth rate, which were grown for 24-36 h) in $20 \mathrm{ml}$ of M9 glucose minimal used to seed working cultures to an optical density measured at $600 \mathrm{~nm}\left(\mathrm{OD}_{600}\right)$ of ca. 0.05 . Normalized growth coefficients were calculated according to Nikel et al. (2013). In the case of solid culture media, the composition was the same of the corresponding liquid media with the addition of $15 \mathrm{~g} \mathrm{l}^{-1}$ of agar. The antibiotics employed for selection were added whenever needed at the following final concentrations: ampicillin (Ap), $150 \mu \mathrm{g} \mathrm{ml}^{-1}$ for E. coli strains or $500 \mu \mathrm{g} \mathrm{ml}^{-1}$ for $P$. putida strains; gentamicin $(\mathrm{Gm}), 10 \mu \mathrm{g} \mathrm{ml}^{-1}$; and kanamycin $(\mathrm{Km}), 50 \mu \mathrm{g} \mathrm{ml}^{-1}$. In some cultures, isopropyl-1-thio- $\beta$-galactopyranoside (IPTG) was added at $1 \mathrm{mM}$ to induce the LaclQ/P $P_{\text {trc }}$ expression system. During the construction of $P$. putida mutants, sodium 3-methylbenzonate (3$\mathrm{mBz}$ ) was used at $15 \mathrm{mM}$ to induce the XylS-dependent $\mathrm{Pm}$ promoter, driving the expression of the gene encoding the I-Scel homing nuclease. The same inducer (3-mBz) was used at $0.5 \mathrm{mM}$ to trigger the XylS/Pm-dependent expression of the crt genes in carotenoid synthesis experiments. For long-term preservation, bacteria were frozen in LB medium containing $20 \%(\mathrm{v} / \mathrm{v})$ glycerol and kept at $-80^{\circ} \mathrm{C}$.

2.2. DNA manipulation and sequencing, construction of mutant strains and assembly of a synthetic pathway for carotenoid synthesis, and bacterial transformation

The plasmids and oligonucleotides used in this study are listed in Table $\mathbf{S 1}$ and $\mathbf{S 2}$, respectively, in the Supplementary Material. DNA manipulations were carried out following routine laboratory techniques (Green and Sambrook, 2012). Plasmid DNA purification was done with the QIAprep Spin Miniprep kit (Qiagen Inc., Valencia, CA, USA) according to the manufacturer's instructions. 
1 Restriction and DNA modification enzymes were purchased from New England BioLabs (Ipswich,

2 MA, USA). Synthetic oligonucleotides were ordered from Sigma-Aldrich (St. Louis, MO, USA).

3 Isolate colonies from fresh LB plates were used as the starting material for colony polymerase

4 chain reaction (PCR) amplifications to check for the presence of plasmids or gene deletions. PCR 5 products were purified with the NucleoSpin Extract II kit (Macherey-Nagel, Düren, Germany).

6 Agarose gel visualization was possible with the use of VersaDoc ${ }^{\mathrm{TM}}$ apparatus (Bio-Rad Corp., 7 Hercules, CA, USA). DNA sequencing (Secugen, Madrid, Spain) was used to check the accuracy 8 of all constructs. Clean P. putida mutants were obtained following the protocol described by 9 Martínez-García and de Lorenzo (2011); the detailed protocol for the construction of mutants is 10 described in the Supplementary Material. Plasmid pPS1.CRT, carrying the crtEB/Y genes from 11 the Gram-negative Enterobacterium Pantoea ananatis (Table S1 in the Supplementary Material), 12 was constructed for carotenoid synthesis. The expression plasmid was assembled by means of 13 USER cloning (Nour-Eldin et al., 2010). Individual DNA fragments were amplified by PCR using 
3 The function of some genes, for which no experimental data was available, has been explored in 4 silico using curated genome databases. The web resources used in this study were the 5 MicroScope platform available at http://www.genoscope.cns.fr/agc/microscope (Vallenet et al., 6 2017) and the Pseudomonas Genome Database available at http://www.pseudomonas.com 7 (Winsor et al., 2016).

\subsection{In silico prediction of gene function and use of online databases}

\subsection{Preparation of cell-free extracts and in vitro enzymatic assays}

Cell-free extracts of $E$. coli and $P$. putida were obtained by a modification of published protocols (Chavarría et al., 2016; Corona et al., 2018; Nikel et al., 2014a; Ruiz et al., 2006). A detailed description of the procedures and the specific methods used for in vitro assays of Edd, Gad, Gcd, Glk, and Pfk can be found in the Supplementary Material. The limit of detection for all the enzymatic assays described in this study was below $2 \mathrm{nmol} \mathrm{min}^{-1} \mathrm{mg}_{\text {protein-1. }}$.

\subsection{Other analytical determinations}

Experiments requiring quantification of residual glucose in culture supernatants were performed by adapting a protocol based on the glucose assay kit (Sigma-Aldrich Co.) into 96-well microtiter plates (Nunclon ${ }^{\mathrm{TM}} \Delta$ Surface; Nunc A/S, Roskilde, Denmark). The assay reagent was prepared as indicated in the technical bulletin; the final mix per well contained $80 \mu$ of the assay reagent, 40 $\mu \mathrm{l}$ of the sample (diluted with water to yield approximately 20-80 $\mu \mathrm{g}$ glucose $\mathrm{ml}^{-1}$ ), and $80 \mu \mathrm{l}$ of 12 $\mathrm{N} \mathrm{H}_{2} \mathrm{SO}_{4}$. The amount of the final pink-colored product (oxidized o-dianisidine) was quantified at $540 \mathrm{~nm}$ using a SpectraMax ${ }^{\mathrm{TM}}$ M2e multi-mode microplate reader (Molecular Devices LLC, Sunnyvale, CA, USA). The supernatants for these determinations were obtained by centrifugation of $50-\mathrm{ml}$ cultures harvested in mid-exponential phase (i.e. corresponding to an $\mathrm{OD}_{600}$ of ca. 0.5 ) at 4000 r.p.m. for $15 \mathrm{~min}$ at $4^{\circ} \mathrm{C}$. 


\subsection{Quantification of intracellular metabolite concentrations}

3 P. putida cultures (the wild-type strain carrying the empty vector pSEVA224, and the GC1 mutant 4 harboring plasmid pS224.GBI) were grown in M9 minimal medium added with glucose at $20 \mathrm{mM}$, $550 \mu \mathrm{g} \mathrm{ml}^{-1} \mathrm{Km}$, and $1 \mathrm{mM}$ IPTG. When the cultures reached the mid-exponential phase (i.e. $6 \mathrm{OD}_{600}$ of ca. 0.5), the biomass corresponding to $0.5-0.6 \mathrm{mg}$ of cell dry weight (CDW) was 7 collected in duplicates by fast centrifugation (13,000 r.p.m., $\left.30 \mathrm{~s},-4^{\circ} \mathrm{C}\right)$. Bacterial pellets were 8 immediately frozen by immersing the cell sediment in liquid $\mathrm{N}_{2}$. Samples were then extracted 9 three times with $0.5 \mathrm{ml}$ of $60 \%(\mathrm{v} / \mathrm{v})$ ethanol buffered with $10 \mathrm{mM}$ ammonium acetate $(\mathrm{pH}=7.2)$ at $1078^{\circ} \mathrm{C}$ for $1 \mathrm{~min}$. After each extraction step, the biomass was separated by centrifugation at 13,000 r.p.m. for $1 \mathrm{~min}$. The three liquid extracts were pooled in a new tube and dried at $120 \mu \mathrm{bar}$, and finally stored at $-80^{\circ} \mathrm{C}$. Samples were re-suspended in $20 \mu \mathrm{l}$ of MilliQ water and injected into a Waters Acquity UPLC system (Waters Corp., Milford, MA, USA) with a Waters Acquity T3 column (150 mm $\times 2.1 \mathrm{~mm} \times 1.8 \mu \mathrm{m}$, Waters Corp.) coupled to a Thermo TSQ Quantum Ultra triple quadrupole instrument (Thermo Fisher Scientific Inc., Waltham, MA, USA) with electrospray ionization. The quantitative analysis of raw metabolomic data and the normalization procedure were conducted as explained by van der Werf et al. (2008) and Nikel et al. (2015). Carotenoids were analytically quantified by extracting the biomass upon harvesting cells from 24-h glucose cultures in M9 minimal medium (added with glucose, Km, Gm, IPTG, and 3-mBz). Cell material, corresponding to an $\mathrm{OD}_{600}=3$, was harvested by centrifugation (13,000 r.p.m., 5 min, $4^{\circ} \mathrm{C}$ ). Cells were resuspended in $50 \mu \mathrm{l}$ of water before extraction with $1 \mathrm{ml}$ of acetone, and all the operations were carried out in the dark. The bacterial biomass was extracted with the solvent three times; the extracts were pooled and dried under a gentle $\mathrm{N}_{2}$ current. Dried extracts were kept at $-80^{\circ} \mathrm{C}$ until analysis, when the sediment was resuspended in $20 \mu \mathrm{l}$ of ethanol just prior to analysis. Pigment extracts were centrifuged again as indicated above, and the absorption was immediately determined spectrophotometrically at $450 \mathrm{~nm}$. Total carotenoid concentrations were assessed in these samples using a molar extinction coefficients for $\beta, \beta$-carotene of $\varepsilon=140,500 \mathrm{M}^{-1} \mathrm{~cm}^{-1}$ (Britton et al., 2004). Ethanolic extracts were also subjected to gas chromatography coupled to mass spectrometry (GC-MS) analysis for precise carotenoid quantification as indicated by Stutz et al. (2015). 
1 2.7. Analysis of the contribution of the synthetic glycolysis to pyruvate biosynthesis by positional 2 enrichment using ${ }^{13} \mathrm{C}$-labelled substrates

4 The relative contribution of the EMP, ED, and PP pathways to glucose catabolism (at the level of 5 the Pyr node) was assessed by analyzing the ${ }^{13} \mathrm{C}$-labeling pattern of proteinogenic alanine (Ala), generated during growth on $\left[{ }^{1-13} \mathrm{C}_{1}\right]$-glucose. To this end, the bacterial strains under study were grown as indicated in Sections 2.1 and 2.6, but using [1-13 $\left.C_{1}\right]$-glucose (Cambridge Isotope

8 Laboratories, Tewksbury, MA, USA) at $20 \mathrm{mM}$ as the carbon source. Inocula for these working 9 cultures were likewise prepared in the presence of $20 \mathrm{mM}\left[1-{ }^{13} \mathrm{C}_{1}\right]$-glucose. Cells were collected 10 from $10-\mathrm{ml}$ culture aliquots by centrifugation (10,000 r.p.m., $5 \mathrm{~min}, 4^{\circ} \mathrm{C}$ ) when the cultures reached $\mathrm{OD}_{600}=0.5$, and pellets were rapidly washed twice with deionized water. Prior to GC-MS analysis, the cellular protein was hydrolyzed for $24 \mathrm{~h}$ at $105^{\circ} \mathrm{C}$ using $50 \mu \mathrm{l}$ of $6 \mathrm{M} \mathrm{HCl}$ per mg of CDW (Nikel et al., 2015). Cell debris was removed by filtration (Ultrafree-MC centrifugal filter; Millipore, Billerica, MA, USA). The labeling patterns of proteinogenic Ala were analyzed using its tert-butyldimethylsilyl derivative (Nanchen et al., 2007) in an Agilent 7890A GC-MS equipped with a 5975C quadrupole mass selective detector (Agilent Technologies, Waldbronn, Germany). The relative fraction of the non-labeled mass isotopomers $\left(M_{0}\right)$ of the entire Ala molecule with carbon atoms $C_{1}, C_{2}$, and $C_{3}\left(A_{1}^{123}\right)$ and of a fragment that contained the two carbon atoms $C_{2}$ and $C_{3}$ (Ala ${ }^{23}$ ) were assessed to determine the origin of Pyr essentially as explained by Klingner et al. (2015). Individual labeled fractions were obtained from mass analysis of tertbutyldimethylsilyl-derivatized Ala at a mass-to-charge $(\mathrm{m} / \mathrm{z})$ ratio for the monoisotopic mass of $260\left(\mathrm{Ala}^{123}\right)$ and $232\left(\mathrm{Ala}^{23}\right)$. Natural isotope abundances in the samples were corrected as explained by Nikel et al. (2009). Anaplerotic fluxes were accounted for by the amount of oxaloacetate derived from Pyr, and phosphoenolpyruvate derived from oxaloacetate (Chavarría et al., 2012). The relative fluxes into the ED pathway ( $\left.f_{\mathrm{ED}}\right)$, the EMP pathway $\left(f_{\mathrm{EMPP}}\right)$, and the PP pathway $\left(f_{\mathrm{PP}}\right)$ were derived from these measurements as $f_{\mathrm{ED}}=1-f_{\mathrm{PP}}-f_{\mathrm{EMP}}, f_{\mathrm{EMP}}=-2 \times\left(M_{0}, \mathrm{Ala}^{23}\right.$ $-1)$, and $f_{P P}=2 \times\left(M_{0}, A_{1} a^{123}-0.5\right)$, respectively. The calculation of the respective fluxes via the labeling pattern of proteinogenic serine (Fürch et al., 2009) yielded the same results. 


\subsection{Data and statistical analysis}

3 All the experiments reported were independently repeated at least twice (as indicated in the 4 corresponding figure or table legend), and the mean value of the corresponding parameter \pm 5 standard deviation is presented. In some cases, the level of significance of the differences when comparing results was evaluated by means of the Student's $t$ test with $\alpha=0.01$ or $\alpha=0.05$ as

7 indicated in the figure legends.

\section{Results and Discussion}

We started by inspecting the biochemical reactions in central carbon metabolism of $P$. putida KT2440 (Fig. 2) that should be eliminated for constructing a glycolytic chassis (GC) that could host an artificially-assembled EMP glycolytic route. Core (trunk) and peripheral pathways for sugar processing were targeted for substrate channeling into the intended synthetic route. Glucose can be processed in two different ways in P. putida KT2440: (i) direct phosphorylation in the cytoplasm via the glucokinase activity (Glk) encoded by the glk gene (PP_1011), and (ii) oxidation in the periplasmic space via the glucose dehydrogenase activity (Gcd) encoded by the gcd gene (PP_1444) and the gluconate 2-dehydrogenase activity (Gad), the genetic source of which is yet to be defined. We thus set to eliminate the genes encoding all three enzymatic activities in strain KT2440 and to identify, at the same time, the genetic determinants of the Gad activity in this bacterium.

The first issue to solve was the branching generated by the Glk and Gcd activities. The glk gene encodes the main (and probably only) hexose kinase activity in P. putida KT2440 (del Castillo et al., 2007). Glk converts glucose into glucose-6-P (G6P) in the cytoplasm (Fig. 2), and this metabolic intermediate can be transformed into 6PG by the sequential action of Zwf (G6P dehydrogenase, represented by three isozymes in strain KT2440) and Pgl (6phosphogluconolactonase). 6PG stemming from this phosphorylation branch represents ca. 10\% of the glucose entering the core biochemical network (Nikel et al., 2015), which indicates that the 
1 peripheral oxidation loop for sugars is preferred in this bacterial species. The Gcd activity is 2 executed by the protein encoded by the single gcd gene (PP_1444) (del Castillo et al., 2007). 3 This enzyme is an example of inner membrane-bound glucose dehydrogenase (An and Moe, 4 2016), that requires the redox cofactor pyrroloquinoline quinone (PQQ). Gcd allows $P$. putida 5 KT2440 to transform glucose into gluconate in the periplasmic space (Fig. 2)-a rather relevant role if one considers that almost $90 \%$ of the glucose that enters the central carbon metabolism of this bacterium gets oxidized (Nikel et al., 2015). Transformation of glucose into oxidized products

8 is counterproductive for our engineering purposes, as the use of hexoses in peripheral reactions competes with the intended linear glycolysis.

On this basis, the glk and gcd genes in strain KT2440 were independently eliminated and the biochemical characterization and growth profile displayed by the parental strain was compared to the $\Delta g l k$ and $\Delta g c d$ mutants (Fig. 3). Deletion of glk and $g c d$ resulted in the loss of any detectable Glk and Gcd activity, respectively, in the corresponding P. putida mutants (Fig. 3a). At the same time, individually blocking either the phosphorylative $(\Delta g / k)$ or the oxidative $(\Delta g c d)$ branches of hexose processing did not result in any evident cross-regulation effects on the other (remaining) activity. In other words, removing the Glk activity from $P$. putida does not result in a different pattern of Gcd activity-and vice versa. The glucose-dependent growth of the $\Delta g c d$ mutant was more affected than that of the $\Delta g / k$ strain ( $\mu=0.33 h^{-1}$ versus $\mu=0.45 h^{-1}$, respectively) when bacteria were grown in M9 minimal medium with $20 \mathrm{mM}$ glucose as the sole carbon source (Fig. 3b). The growth phenotype of the $\Delta g c d$ strain did not involve a dramatic effect in terms of overall fitness (as indicated by the extension of the lag phase and final biomass density, which did not differ significantly from the values observed in the parental strain)—but, again, it could reflect the preference of this bacterium to metabolize glucose mainly by the oxidative branch. Additionally, the absence of Glk and Gcd activities were not deemed relevant for growth under gluconeogenic conditions, i.e. in M9 minimal medium with $30 \mathrm{mM}$ succinate (Fig. 3b). Interestingly, the growth rates recorded for all the strains under study in microtiter plate cultures were similar, irrespective of the substrate used. As expected, the accumulation of the $\Delta g / k$ and $\Delta g c d$ deletions in the same strain prevented the resulting mutant from growing on glucose as the sole carbon source. This observation contrasts with the marginal impact that the individual deletions displayed on growth, highlighting the robustness of central carbon metabolism in P. putida KT2440. 
1 3.2. Identification of genes encoding 2-gluconate dehydrogenase (Gad) in P. putida KT2440 and 2 construction of a strain devoid of Gad activity

4 Even when blocking the Gcd step of the peripheral oxidation loop was enough to prevent the 5 utilization of glucose via the oxidative branch, we explored the genetic determinants of the Gad activity in strain KT2440 to avoid potential misrouting of metabolic intermediates or unexpected interactions due to the presence of latent oxidative activities (Miller and Raines, 2004). Based on the in silico analysis of the genome of $P$. putida KT2440, the Gad activity is presumed to be catalyzed by an enzymatic complex comprising three different gene products: PP_3382, adenine dinucleotide (FAD)-containing gluconate 2-dehydrogenase (FAD-GADH) (Mclntire et al., 1985). Such FAD-GADH activity has been characterized to some extent in $P$. aeruginosa (Hunt and Phibbs, 1983; Matsushita et al., 1982), allowing us to identify the orthologues in P. putida KT2440. Analysis of the corresponding genomic regions revealed the following features: (i) the largest subunit of the complex is encoded by PP_3383 (with a product of 594 amino acids) and comprises the dehydrogenase subunit that contains FAD as the prosthetic group, covalently bound to the histidine residue of the polypeptide (Mclntire et al., 1985); (ii) the middle subunit (with a product of 417 amino acids) is encoded by PP_3382 and contains the heme c cofactor, which probably facilitates the electron transfer from the FAD moiety in the dehydrogenase to the ubiquinone carrier in the inner membrane, thus connecting sugar oxidation with the respiratory chain (Matsushita et al., 1994); and (iii) the small subunit (with a product of 246 amino acids) is encoded by PP_3384 and it was recently annotated in silico as a $\gamma$ subunit of the FAD-GADH complex (Belda et al., 2016).

Despite the fact that the literature offers examples of biotechnological applications based on the use of the PP_3382-4 enzymatic complex (Yu et al., 2018), the function of Gad has not been yet proved via generation of mutant $P$. putida strains. In this work, the complete, in-frame removal of the group of genes PP_3382-4 was achieved by a single deletion event. The gene pair PP_3382 and PP_3383 has a properly annotated function both in the Pseudomonas database (Winsor et al., 2016) and in the resequencing of the genome of strain KT2440 (Belda et al., 2016). As indicated above, PP_3384 has been annotated in silico as $\gamma$ subunit of the FAD-GADH complex, 
1 and it was removed taking into account studies in other bacterial species, indicating a key role of 2 FAD-GADH in sugar oxidation (Arellano et al., 2010). Additionally, the relevance of the products encoded by PP_3623 and PP_4232 in the overall Gad activity was evaluated by eliminating the corresponding coding sequences. The in silico annotation identifies PP_3623 (encoding a product of 447 amino acids), as the cytochrome $c$ subunit of an alcohol dehydrogenase. At the same time, PP_3623 is considered to be a duplication of PP_3382 with a high level of statistical significance. PP_4232 (encoding a product of 403 amino acids) has not been assigned any function but is also considered to be a PP_3382 duplication. Taking into account this information, the deletion of both time, on the existing knowledge about oxidative carbon metabolism in strain KT2440.

According to the results of Fig. $\mathbf{4 b}$, the pool of genes involved in the oxidation of gluconate into $2-$ ketogluconate could be unambiguously identified. The bulk Gad activity could be traced to the products encoded by the PP3382-4 operon; the polypeptides encoded by PP_3623 and PP_4232 displaying a marginal influence in the Gad activity. On the other hand, the removal of the Gad activity resulted largely irrelevant in terms of bacterial fitness, since very similar specific growth rates were observed in all the $P$. putida mutants and the parental strain when evaluated under glycolytic (M9 minimal medium with $20 \mathrm{mM}$ glucose) or gluconeogenic (M9 minimal medium with $30 \mathrm{mM}$ succinate) growth conditions (Fig. 4c). Once the peripheral pathways of sugar utilization had been eliminated, we set out to block the default catabolic route for G6P as explained below.

\subsection{Elimination of the Entner-Doudoroff pathway in P. putida KT2440 and physiological characterization of mutant strains}

Given the lack of Pfk in P. putida (Latrach-Tlemçani et al., 2008; Vicente and Cánovas, 1973a, b), the only way that glucose can be metabolized in this species is through the ED pathway. This route enables $P$. putida KT2440 to obtain Pyr and GA3P from glucose-key intermediates for hexoses- $P$ regeneration through the EDEMP cycle-and to obtain energy and reducing power by means of the tricarboxylic acid cycle (Nikel et al., 2016; 2015). The ED pathway is composed by the sequential activity of Edd, encoded by the edd gene (PP_1010), which transforms 6PG into 2- 
1 keto-3-deoxy-6-phosphogluconate (KDPG); and Eda, encoded by the eda gene (PP_1024), 2 which transforms KDPG into Pyr and GA3P (Nikel et al., 2014b). The next stage in the stepwise 3 construction of $P$. putida GC was to remove the first component of ED catabolism (i.e. the Edd 4 activity). Under this scenario, P. putida would be unable to grow on glucose as a sole carbon 5 source-and its glucose-dependent growth phenotype can only be rescued by the functional 6 implementation of a linear glycolysis. Fig. 5 summarizes the growth phenotypes of the in-frame $P$. 7 putida mutants constructed thus far under both glycolytic and gluconeogenic growth conditions.

8 Moreover, the normalized growth coefficients calculated from growth parameters in liquid cultures 9 indicate that (i) the $\Delta g c d$ mutant is the only strain slightly affected when growing on glucose as 10 the sole carbon source, and (ii) the $\Delta g c d \Delta g l k$ double mutant and the $\Delta e d d$ mutant are unable to 11 grow on glucose, and are affected even under gluconeogenic growth conditions. With all this

3.4. Construction of a glycolytic chassis and metabolic grafting of a synthetic EMP device into $P$. putida KT2440

Our previous efforts in activating an EMP pathway in $P$. putida indicated that the mere knock-in of a Pfk activity into the native biochemical network is not only insufficient to enable a linear glycolysis, but also detrimental for the overall cell physiology (Chavarría et al., 2013). Against this background, our current engineering approach included (i) multiple knock-out of genes encoding both central and peripheral routes for sugar metabolism in P. putida and (ii) controlled expression [by means of an IPTG-inducible LaclQ/Ptrc regulatory element; Silva-Rocha et al. (2013)] of a standardized gene cluster encoding the five enzymes of the preparatory phase of the EMP pathway. A strain was thereby constructed by accumulation of the in-frame $\Delta g / k, \Delta g c d, \Delta g a d$ (i.e. $\triangle P P \_3382-4, \Delta P P \_3623$, and $\triangle P P \_4232$ ), and $\Delta e d d$ mutations in $P$. putida KT2440, resulting in P. putida GC1 (Table 1). Upon introduction of Module I of the GlucoBrick platform (SánchezPascuala et al., 2017; 2018) in the P. putida GC1 strain, the expected carbon flow would connect G6P with Pyr via the designed EMP pathway (Fig. 6a). Note that we decided to implement the whole Module I of the linear glycolysis of $E$. coli (although some enzymes of the pathway are 
1 native to $P$. putida GC1) to ensure improved metabolic channeling and reducing the risk of 2 potential bottlenecks in the biochemical network (Hollinshead et al., 2016).

4 A simple growth experiment was first carried out by streaking the bacterial strains under study 5 onto M9 minimal medium plates containing either glucose or succinate and the appropriate 6 additives (Fig. 6b). Both the wild-type strain and P. putida GC1 were transformed either with the 7 empty, low-copy-number pSEVA224 vector or the plasmid expressing Module I from the 8 GlucoBrick platform (pS224.GBI), and plates were incubated for $36 \mathrm{~h}$ at $30^{\circ} \mathrm{C}$. Expectedly, both 9 strains grew well under gluconeogenic conditions (i.e. using succinate), and $P$. putida GC1 10 carrying pSEVA224 could not grow on glucose as the sole carbon source. In contrast, P. putida 11 GC1 transformed with plasmid $\mathrm{pS} 224 \cdot \mathrm{GBI}$ was able to grow on glucose in a similar fashion as observed in succinate-containing plates. In other words, the enzyme activities encoded in Module I allowed P. putida GC1 to metabolize glucose via the synthetic EMP pathway. Since all the strains grew on succinate as the sole carbon source, the genetic manipulations of strain GC1 do not seem to significantly affect bacterial growth via gluconeogenesis. Further characterization of the strains at stake in liquid cultures confirmed the growth phenotypes observed in solid media (Fig. 6c). In glucose cultures, the specific growth rate of $P$. putida GC1 transformed with plasmid pS224.GBI was ca. $10 \%$ of that in the wild-type strain containing the empty vector. This impaired growth is somewhat expected due to the large number of modifications introduced in strain GC1-including several mutations in native components of central carbon metabolism, which are likely preferred over exogenous routes. Oxygen limitation could also play a role, considering that P. putida is an obligate aerobe (Nikel and de Lorenzo, 2013b). In addition to the decrease in the specific growth rate, the final cell density was also affected in cultures of $P$. putida GC1 transformed with plasmid pS224.GBI (i.e. a 35\% reduction in the final $\mathrm{OD}_{600}$ values as compared to that of $P$. putida KT2440 transformed with pSEVA224). In any case, the glucose-dependent growth phenotype served as a proof-of-concept that the designed glycolytic device was functional in the rewired $P$. putida strain. Yet, what are the levels of the key enzymatic activities in this engineered strain? 
1 3.5. Biochemical and metabolomic characterization of the glycolytic device implanted in P. putida

$2 \quad K T 2440$

4 Once the possibility of implementing a functional linear EMP pathway in $P$. putida GC1 as the 5 sole glycolytic route was demonstrated, the observed glucose-dependent growth phenotype was correlated with the presence of enzymes encoded by the GlucoBrick genes. To this end, the Glk and Pfk activities (the first enzyme of the synthetic glycolytic device and the enzyme missing in strain KT2440, respectively) were determined in cell-free extracts of the relevant strains grown in M9 minimal medium containing glucose (Fig. 7). The native Glk activity could be detected in $P$. empty vector (i.e. pSEVA224), upon induction of gene expression with IPTG. The Glk activity in strain KT2440 was almost twice that of $E$. coli (Fig. 7a). The same activity was determined in $P$. putida KT2440 $\Delta g / k$ and in E. coli BW25113 $\Delta g / k \Delta$ ptsl (i.e. an E. coli strain completely deficient in glucose phosphorylation), carrying the empty pSEVA224 vector and added with IPTG. Predictably, no significant Glk activity was detected in either mutant. Finally, hexose phosphorylation was tested in P. putida GC1 containing plasmid pS224.GBI. The only possible way for this bacterium to grow on glucose is linked to the presence of the Glk activity encoded by Module I of the GlucoBrick platform. Indeed, P. putida GC1 carrying plasmid pS224.GBI (and induced with IPTG) had a specific Glk activity 130-fold higher than that of the wild-type strain carrying the empty plasmid (Fig. 7a). This high level of enzyme activity can result from unregulated expression of the glk gene, alongside to the extra gene copies in the cells due to the expression of Module I in a plasmid format-and also from a potentially different pattern of enzyme regulation of Glk from E. coli in a heterologous context (Heredia et al., 2006).

The specific Pfk activity was likewise assessed in E. coli BW255113 and its $\Delta p f k A \Delta p f k B$ double mutant derivative (termed $\Delta$ pfk in Fig. 7b) carrying the empty pSEVA224 vector in IPTG-induced glucose cultures. The Pfk activity was determined in these two E. coli strains as a positive and negative control of F6P phosphorylation, respectively, considering that $P$. putida KT2440 lacks the Pfk-dependent conversion of F6P into FBP (Fig. 2). As expected, the Pfk activity tested positive in the wild-type $E$. coli strain, in contrast to the very low level of activity detected in $E$. coli $\Delta$ pfk and in P. putida KT2440 carrying the empty pSEVA224 vector (Fig. 7b). It was assumed 
1 that the Pfk activity must be present in P. putida GC1 carrying plasmid pS224.GBI, as this would 2 be the only way to bestow growth on glucose. The in vitro biochemical determinations support 3 this notion, as the engineered strain had a 32-fold increase in the Pfk activity compared with wild4 type E. coli BW255113 (Fig. 7b). Similarly to Glk, the high level of Pfk activity detected in P. 5 putida GC1 carrying plasmid pS224.GBI can result from unregulated expression of the pfkA gene 6 [taking into account that this activity is alien to the host; Alves et al. (1997)], alongside to the extra 7 gene copies in the cells due to the expression of Module I in a plasmid format.

9 The implementation of Module I in P. putida GC1 is also expected to result in differences in terms 10 of glucose utilization. The glucose consumption was evaluated during exponential growth of both wild-type $P$. putida KT2440 and P. putida GC1 carrying either an empty PSEVA224 vector or plasmid pS224.GBI, respectively (Fig. 7c). Glucose consumption increased by ca. 2-fold in $P$. putida GC1 bearing plasmid pS224.GBI as compared with the strain KT2440 transformed with the empty pSEVA224 vector. This physiological feature mirrors the increased activity of the enzymes borne by the GlucoBrick platform in P. putida GC1 (Fig. 7a and b). As the pattern of enzymatic activities and sugar consumption was remarkably different in the engineered strain, we also explored its metabolomic fingerprint under the same growth conditions (Table 2). To this end, the intracellular content of the key glycolytic intermediates G6P, fructose-6-P, dihydroxyacetone- $P$, and Pyr were determined both in the parental strain carrying the empty pSEVA224 vector and $P$. putida GC1 transformed with plasmid pS224.GBI by liquid chromatography coupled to mass spectrometry. All metabolic intermediates had increased levels in the engineered strain expressing the glycolytic device; GA3P and Pyr, for instance, had a 2.2and 2.8-fold higher intracellular concentration in P. putida GC1 transformed with plasmid pS224.GBI than in the parental strain bearing an empty vector. These trioses serve as a proxy of the entire glycolytic module, as they are the end-products of hexose catabolism afforded by Module I. The results thus far indicate that the increase in glucose consumption in the engineered P. putida strain was accompanied by high levels of glycolytic intermediates. The next relevant issue is to solve the metabolic origin of Pyr by feeding the engineered strain with isotopicallylabelled substrates as explained in the next section. 
1 3.6. ${ }^{13} \mathrm{C}$-Labelling experiments identify synthetic glycolysis as the main source of pyruvate in 2 engineered P. putida strains

4 When cells are fed with a substrate carrying a positional label such as ${ }^{13} \mathrm{C}$, the isotopic label is 5 passed onto metabolites derived thereof. The resulting labelling pattern can be used to determine the relative activities of different metabolic pathways-and thus the metabolic origin of different intermediates in the biochemical network (Buescher et al., 2015; Fuhrer et al., 2005; Fürch et al.,

Both the wild-type strain transformed with the empty pSEVA224 vector and P. putida GC1 bearing plasmid $p S 224 \cdot G B I$ were grown in $M 9$ minimal medium containing $\left[1-{ }^{13} \mathrm{C}_{1}\right]$-glucose as the sole carbon source; the biomass was harvested during mid-exponential growth, and hydrolyzed to assess the labelling pattern of Ala. When the fraction of Pyr molecules coming from different pathways was analyzed in the control strain, the major source of trioses was found to be the ED pathway (Fig. 8b). In this case, $95 \%$ of Pyr was generated by the activity of the ED route, with a relatively minor contribution from the GA3P $\rightarrow$ Pyr flux via the incomplete EMP pathway and anaplerosis. A negligible involvement of the PP pathway was also evident, in agreement with previous results obtained for wild-type $P$. putida MAD2 (Chavarría et al., 2012). The engineered 
1 P. putida strain expressing the glycolytic module, in contrast, generated $93 \%$ of the Pyr molecules 2 through the synthetic EMP pathway. In vitro measurements of the Edd activity (the first step in the 3 ED pathway) substantiated this result: P. putida GC1 had a very low level of (background) 4 enzyme activity, less than 10\% of that in the wild-type strain (Fig. 8c). Taken together, these 5 results accredit that (i) the synthetic glycolysis is active in the $P$. putida GC1 background, 6 functionally replacing the native ED route, and (ii) the implanted metabolic module serves as the 7 main source of trioses in the engineered strain-enabling glucose-dependent growth. We then 8 focused on the glucose-dependent synthesis of carotenoids as a proof-of-concept application of 9 the engineered glycolytic strains.

\subsection{Enhanced carotenoid synthesis from glucose in engineered P. putida strains}

Carotenoids are tetraterpenoids produced by many organisms (Sandmann, 2015) and, from a biotechnological point of view, these C40 hydrocarbons have gained interest for different applications including their use as nutraceuticals or pharmaceuticals (Schweiggert and Carle, 2016; Zhao et al., 2013). In the carotenogenic Gram-negative species $P$. ananatis, the synthesis of carotenoids involves the sequential action of $\mathrm{CrtE}$ (geranylgeranyl diphosphate synthase), $\mathrm{CrtB}$ (phytoene synthase), Crtl (phytoene desaturase), and CrtY (lycopene cyclase) (Misawa et al., 1990), encoded by the 4.5-kb long crt gene cluster (Fig. 9a). The key metabolic precursors needed for carotenoid synthesis are Pyr and GA3P, which are firstly transformed by the methylerythritol 4-phosphate (MEP pathway) into the C15 intermediate farnesyl pyrophosphate (Fig. 9b). The 4-step carotenoid synthesis pathway finally yields the orange-colored $\beta$-carotene product. We reasoned that the introduction of the carotenoid synthesis pathway in engineered $P$. putida strains carrying the synthetic glycolytic module would result in enhanced synthesis of the tetraterpenoid, since the intracellular supply of both Pyr and GA3P trioses is higher than in the wild-type strain (Table 2). We constructed plasmid pPS1 ·CRT for the 3-mBz-inducible, XyIS/Pmcontrolled expression of the crt genes from $P$. ananatis (Table $\mathbf{S 1}$ in the Supplementary Material), and transformed both the wild-type strain (carrying the empty pSEVA224 vector) and P. putida GC1 (carrying plasmid pS224.GBI) either with plasmid pPS1.CRT or the empty pPS1 vector counterpart. All the engineered strains were aerobically grown in M9 minimal medium containing $20 \mathrm{mM}$ glucose and the appropriate antibiotics and inducers, and the carotenoid content in these 
1 cultures was assessed by GC-MS analysis after $24 \mathrm{~h}$ of induction of the expression of the crt 2 gene cluster (Fig. 9c). Expectedly, we could not detect any carotenoids in acetone extracts 3 obtained from the strains transformed with the empty pPS1 vector. Expression of the crt gene 4 cluster from plasmid pPS1.CRT, in contrast, resulted in carotenoid formation both in wild-type 5 KT2440 and P. putida GC1 carrying the glycolytic module. The total carotenoid content on 6 biomass was 1.3-fold higher in the strain carrying the synthetic glycolysis than in the wild-type 7 strain, reaching $372 \pm 18 \mu \mathrm{g} \mathrm{gcDW}^{-1}$. These values are in good accordance with a previous report 8 exploring $\beta$-carotene biosynthesis in recombinant $P$. putida grown in a rich culture medium 9 (Loeschcke et al., 2013). The yield of carotenoids on glucose was also explored in these cultures 10 as a measure of the efficiency of substrate transformation, and we found that $Y_{\text {carotenoid/glucose }}$ was carbon metabolism.

\section{CONCLUSION}

The metabolic lifestyle of $P$. putida has been evolutionary shaped by the environmental niches where this bacterium thrives. As such, it does not come as a surprise that the metabolic features of this species favor diversity (i.e. number and chemical nature of the substrates-to-be) over efficiency (i.e. energy yield per unit of carbon substrate consumed). Sugars are not readily processed by $P$. putida, and the metabolic network deployed for the consumption of hexoses is plagued by peripheral oxidation pathways in addition to a cyclic operation of catabolism (Nikel et al., 2015) - a feature shared by other Pseudomonas species (Wilkes et al., 2018). Time and again, examples of metabolic engineering approaches in the literature indicate that transforming the identity of central carbon metabolism in microorganisms is not an easy task (Jojima and Inui, 2015)—requiring a combination of rewiring the native biochemical network and tightly-controlled expression of genes encoding the intended catabolic functions. Reports describing approaches that target central carbon metabolism in general, and glycolysis in particular (which fuels bacterial cell factories to obtain energy and precursors needed for growth and bioproduction), are relatively scarce (Bogorad et al., 2013; Chen et al., 2013; Kannisto et al., 2014; Kern et al., 2007; Wang et 
1 al., 2019). Manipulating the core metabolism of bacterial species, which is densely interconnected 2 with the rest of the biochemical network and subjected to complex regulatory patterns, is thus a 3 challenging aspect of metabolic engineering (Papagianni, 2012). However, the tools of 4 contemporary synthetic biology allow for rationally designing alternative metabolic modules 5 (synthetic metabolism) that can be plugged-in and -out of rewired bacterial chassis (Erb et al., 6 2017). By adopting this type of multi-factorial approach, Dvořák and de Lorenzo (2018) recently 7 demonstrated how the range of carbohydrates used by $P$. putida can be broadened to include 8 cellobiose and xylose-two substrates alien to the native catabolic scope of this bacterium. Along 9 this line of reasoning, the present work shows how the catabolism of $P$. putida can be replaced by 10 a rationally-designed glycolytic device. ${ }^{13} \mathrm{C}$-Labelling experiments indicated that the engineered $P$. 11 putida strain described herein generated the bulk of the Pyr pool from the EMP glycolytic route. If the objective is to maximize biomass yield from glucose, the activity and fluxes through the components of the novel metabolic module-as well as its connectivity with the background biochemical network-could be optimized in vivo through the evolutionary exploration of the solution space (Dragosits and Mattanovich, 2013; van den Bergh et al., 2018). The biosynthesis of secondary metabolite products derived from central carbon metabolism, on the other hand, can benefit from the approach undertaken in this study. Carotenoids could be accumulated to significantly higher levels in the engineered strains than in the wild-type (with a higher yield on the substrate), indicating that limited growth rates might be even an advantage for growth-uncoupled bioproduction.

Besides the biotechnological potential of such laboratory-created strains, the data above poses a legitimate question regarding the link between metabolic signatures (metabolic lifestyle) and species identity. The catabolism of sugars and other substrates has traditionally constituted one of the bases for taxonomic classification of bacterial isolates [e.g. in the early editions of the Bergey's Manual of Systematic Bacteriology (Buchanan and Gibbons, 1974)] before the onset of molecular markers such as the sequence of the gene encoding 16S RNA (van Belkum et al., 2001). The predominance of the ED pathway and the lack of Pfk have been considered typical metabolic signatures of Pseudomonads (Sokatch, 1986). The functional replacement of an archetypal biochemical network in a member of the group by a synthetic metabolism may also alter the factual taxonomy of the resulting bacterium. This type of deep metabolic engineering 
1 applied to $P$. putida (and other bacteria) is likely to challenge the current frame for assigning a 2 safety level to the corresponding species-and these developments certainly ask for novel criteria

3 to deal with new-to-Nature biological agents. One way or the other, this work represents a first

4 case example of what could be called metabolic grafting or metabolic surgery in Pseudomonas, 5 and this approach could set the basis for further engineering whole-cell biocatalysts for different 6 biotechnological purposes.

\section{$8 \quad$ AUTHORS' CONTRIBUTIONS}

A.S.P., L.F.C., V.D.L., and P.I.N. designed the experiments. V.D.L. and P.I.N. conceived the whole study and wrote the article. A.S.P. carried out genetic manipulations, quantitative physiology experiments, and in vitro enzyme assays. L.F.C. engineered and analyzed carotenoid biosynthesis in $P$. putida. All the authors contributed to the discussion of the research and interpretation of the data.

\section{ACKNOWLEDGMENTS}

This study was supported by grants from The Novo Nordisk Foundation (grant NNF10CC1016517, and LiFe, NNF180C0034818) and the Danish Council for Independent Research (SWEET, DFF-Research Project 8021-00039B) to P.I.N. and by the HELIOS Project of the Spanish Ministry of Science BIO 2015-66960-C3-2-R (MINECO/FEDER); the ARISYS (ERC2012-ADG-322797), EmPowerPutida (EU-H2020-BIOTEC-2014-2015-6335536), MADONNA (H2020-FET-OPEN-RIA-2017-1-766975), BioRoboost (H2020-NMBP-BIO-CSA-2018), and SYNBIO4FLAV (H2020-NMBP/0500) Contracts of the European Union and the S2017/BMD-3691 InGEMICS-CM funded by the Comunidad de Madrid (Spain) and the European Structural and Investment Funds. L.F.C. is supported by the European Union's Horizon 2020 Research and Innovation Programme under the Marie Skłodowska-Curie grant 713683 (COFUNDfellowsDTU). The authors declare that there are no competing interests associated with the contents of this article. 
Alves, A. M., Euverink, G. J., Bibb, M. J., Dijkhuizen, L., 1997. Identification of ATP-dependent phosphofructokinase as a regulatory step in the glycolytic pathway of the actinomycete Streptomyces coelicolor A3(2). Appl. Environ. Microbiol. 63, 956-961.

An, R., Moe, L. A., 2016. Regulation of pyrroloquinoline quinone-dependent glucose dehydrogenase activity in the model rhizosphere-dwelling bacterium Pseudomonas putida KT2440. Appl. Environ. Microbiol. 82, 4955-4964.

Arellano, B. H., Ortiz, J. D., Manzano, J., Chen, J. C., 2010. Identification of a dehydrogenase required for lactose metabolism in Caulobacter crescentus. Appl. Environ. Microbiol. 76, 3004-3014.

Bagdasarian, M., Lurz, R., Rückert, B., Franklin, F. C. H., Bagdasarian, M. M., Frey, J., Timmis, K. N., 1981. Specific purpose plasmid cloning vectors. II. Broad host range, high copy number, RSF1010-derived vectors, and a host-vector system for gene cloning in Pseudomonas. Gene. 16, 237-247.

Belda, E., van Heck, R. G. A., López-Sánchez, M. J., Cruveiller, S., Barbe, V., Fraser, C., Klenk, H. P., Petersen, J., Morgat, A., Nikel, P. I., Vallenet, D., Rouy, Z., Sekowska, A., Martins dos Santos, V. A. P., de Lorenzo, V., Danchin, A., Médigue, C., 2016. The revisited genome of Pseudomonas putida KT2440 enlightens its value as a robust metabolic chassis. Environ. Microbiol. 18, 3403-3424.

Benedetti, I., de Lorenzo, V., Nikel, P. I., 2016. Genetic programming of catalytic Pseudomonas putida biofilms for boosting biodegradation of haloalkanes. Metab. Eng. 33, 109-118.

Blank, L. M., Ionidis, G., Ebert, B. E., Bühler, B., Schmid, A., 2008. Metabolic response of Pseudomonas putida during redox biocatalysis in the presence of a second octanol phase. FEBS J. 275, 5173-5190.

Bogorad, I. W., Lin, T. S., Liao, J. C., 2013. Synthetic non-oxidative glycolysis enables complete carbon conservation. Nature. 502, 693-697.

Britton, G., Liaaen-Jensen, S., Pfander, H., 2004. Carotenoids. Birkhäuser, Basel, Switzerland.

Buchanan, R. E., Gibbons, N. R., 1974. Bergey's Manual of Determinative Bacteriology, 8th ed. Williams \& Wilkins, Baltimore, MD, USA. 
1 Buescher, J. M., Antoniewicz, M. R., Boros, L. G., Burgess, S. C., Brunengraber, H., Clish, C. B., DeBerardinis, R. J., Feron, O., Frezza, C., Ghesquiere, B., Gottlieb, E., Hiller, K., Jones, R. G., Kamphorst, J. J., Kibbey, R. G., Kimmelman, A. C., Locasale, J. W., Lunt, S. Y., Maddocks, O. D. K., Malloy, C., Metallo, C. M., Meuillet, E. J., Munger, J., Nöh, K., Rabinowitz, J. D., Ralser, M., Sauer, U., Stephanopoulos, G., St-Pierre, J., Tennant, D. A., Wittmann, C., Vander Heiden, M. G., Vazquez, A., Vousden, K., Young, J. D., Zamboni, N., Fendt, S.-M., 2015. A roadmap for interpreting ${ }^{13} \mathrm{C}$ metabolite labeling patterns from cells. Curr. Opin. Biotechnol. 34, 189-201.

Calero, P., Jensen, S. I., Nielsen, A. T., 2016. Broad-host-range ProUSER vectors enable fast characterization of inducible promoters and optimization of $p$-coumaric acid production in Pseudomonas putida KT2440. ACS Synth Biol. 5, 741-753.

Calero, P., Nikel, P. I., 2019. Chasing bacterial chassis for metabolic engineering: A perspective review from classical to non-traditional microorganisms. Microb. Biotechnol. 12, 98-124.

Chavarría, M., Goñi-Moreno, A., de Lorenzo, V., Nikel, P. I., 2016. A metabolic widget adjusts the phosphoenolpyruvate-dependent fructose influx in Pseudomonas putida. mSystems. 1, e00154-16.

Chavarría, M., Kleijn, R. J., Sauer, U., Pflüger-Grau, K., de Lorenzo, V., 2012. Regulatory tasks of the phosphoenolpyruvate-phosphotransferase system of Pseudomonas putida in central carbon metabolism. mBio. 3, e00028-12.

Chavarría, M., Nikel, P. I., Pérez-Pantoja, D., de Lorenzo, V., 2013. The Entner-Doudoroff pathway empowers Pseudomonas putida KT2440 with a high tolerance to oxidative stress. Environ. Microbiol. 15, 1772-1785.

Chen, R. R., Agrawal, M., Mao, Z., 2013. Impact of expression of EMP enzymes on glucose metabolism in Zymomonas mobilis. Appl. Biochem. Biotechnol. 170, 805-818.

Choi, K. H., Kumar, A., Schweizer, H. P., 2006. A 10-min method for preparation of highly electrocompetent Pseudomonas aeruginosa cells: application for DNA fragment transfer between chromosomes and plasmid transformation. J. Microbiol. Methods. 64, 391-397.

Corona, F., Martínez, J. L., Nikel, P. I., 2018. The global regulator Crc orchestrates the metabolic robustness underlying oxidative stress resistance in Pseudomonas aeruginosa. Environ. Microbiol. 21, 898-912. 
1 Datsenko, K. A., Wanner, B. L., 2000. One-step inactivation of chromosomal genes in Escherichia coli K-12 using PCR products. Proc. Natl. Acad. Sci. USA. 97, 6640-6645.

3 de Lorenzo, V., Loza-Tavera, H., 2011. Microbial bioremediation of chemical pollutants: How bacteria cope with multi-stress environmental scenarios. In: Storz, G., Hengge, R. (Eds.), Bacterial Stress Responses, 2nd Edition. American Society of Microbiology, Washington D.C., pp. 481-492.

del Castillo, T., Duque, E., Ramos, J. L., 2008. A set of activators and repressors control peripheral glucose pathways in Pseudomonas putida to yield a common central intermediate. J. Bacteriol. 190, 2331-2339.

del Castillo, T., Ramos, J. L., Rodríguez-Herva, J. J., Fuhrer, T., Sauer, U., Duque, E., 2007. Convergent peripheral pathways catalyze initial glucose catabolism in Pseudomonas putida: Genomic and flux analysis. J. Bacteriol. 189, 5142-5152.

Dragosits, M., Mattanovich, D., 2013. Adaptive laboratory evolution - Principles and applications for biotechnology. Microb. Cell Fact. 12, 64.

Dvořák, P., de Lorenzo, V., 2018. Refactoring the upper sugar metabolism of Pseudomonas putida for co-utilization of cellobiose, xylose, and glucose. Metab. Eng. 48, 94-108.

Dvorák, P., Nikel, P. I., Damborský, J., de Lorenzo, V., 2017. Bioremediation 3.0: Engineering pollutant-removing bacteria in the times of systemic biology. Biotechnol. Adv. 35, 845866.

Ebert, B. E., Kurth, F., Grund, M., Blank, L. M., Schmid, A., 2011. Response of Pseudomonas putida KT2440 to increased NADH and ATP demand. Appl. Environ. Microbiol. 77, 65976605.

Erb, T. J., Jones, P. R., Bar-Even, A., 2017. Synthetic metabolism: metabolic engineering meets enzyme design. Curr. Opin. Chem. Biol. 37, 56-62.

Flamholz, A., Noor, E., Bar-Even, A., Liebermeister, W., Milo, R., 2013. Glycolytic strategy as a tradeoff between energy yield and protein cost. Proc. Natl. Acad. Sci. USA. 110, 1003910044.

Fuhrer, T., Fischer, E., Sauer, U., 2005. Experimental identification and quantification of glucose metabolism in seven bacterial species. J. Bacteriol. 187, 1581-1590.

Fürch, T., Preusse, M., Tomasch, J., Zech, H., Wagner-Döbler, I., Rabus, R., Wittmann, C., 2009. Metabolic fluxes in the central carbon metabolism of Dinoroseobacter shibae and 
Phaeobacter gallaeciensis, two members of the marine Roseobacter clade. BMC Microbiol. 9, 209.

Green, M. R., Sambrook, J., 2012. Molecular cloning: a laboratory manual. Cold Spring Harbor Laboratory Press, Cold Spring Harbor, NY.

Hanahan, D., Meselson, M., 1983. Plasmid screening at high colony density. Methods Enzymol. 100, 333-342.

Heredia, V. V., Thomson, J., Nettleton, D., Sun, S., 2006. Glucose-induced conformational changes in glucokinase mediate allosteric regulation: Transient kinetic analysis. Biochemistry. 45, 7553-7562.

Hollinshead, W. D., Rodriguez, S., García-Martín, H., Wang, G., Baidoo, E. E. K., Sale, K. L., Keasling, J. D., Mukhopadhyay, A., Tang, Y. J., 2016. Examining Escherichia coli glycolytic pathways, catabolite repression, and metabolite channeling using $\Delta p f k$ mutants. Biotechnol. Biofuels. 9, 212.

Hunt, J. C., Phibbs, P. V., 1983. Regulation of alternate peripheral pathways of glucose catabolism during aerobic and anaerobic growth of Pseudomonas aeruginosa. J. Bacteriol. 154, 793-802.

Jiménez, J. I., Miñambres, B., García, J. L., Díaz, E., 2002. Genomic analysis of the aromatic catabolic pathways from Pseudomonas putida KT2440. Environ. Microbiol. 4, 824-841.

Jojima, T., Inui, M., 2015. Engineering the glycolytic pathway: A potential approach for improvement of biocatalyst performance. BioEngineered. 6, 328-334.

Kannisto, M., Aho, T., Karp, M., Santala, V., 2014. Metabolic engineering of Acinetobacter baylyi ADP1 for improved growth on gluconate and glucose. Appl. Environ. Microbiol. 80, 70217027.

Kern, A., Tilley, E., Hunter, I. S., Legisa, M., Glieder, A., 2007. Engineering primary metabolic pathways of industrial micro-organisms. J. Biotechnol. 129, 6-29.

Kim, S. H., Cavaleiro, A. M., Rennig, M., Nørholm, M. H., 2016. SEVA Linkers: A versatile and automatable DNA backbone exchange standard for Synthetic Biology. ACS Synth. Biol. $5,1177-1181$.

Klingner, A., Bartsch, A., Dogs, M., Wagner-Döbler, I., Jahn, D., Simon, M., Brinkhoff, T., Becker, J., Wittmann, C., 2015. Large-scale ${ }^{13} \mathrm{C}$ flux profiling reveals conservation of the Entner- 
Doudoroff pathway as a glycolytic strategy among marine bacteria that use glucose. Appl. Environ. Microbiol. 81, 2408-2422.

Kohlstedt, M., Wittmann, C., 2019. GC-MS-based ${ }^{13} \mathrm{C}$ metabolic flux analysis resolves the parallel and cyclic glucose metabolism of Pseudomonas putida KT2440 and Pseudomonas aeruginosa PA01. Metab. Eng. 54, 35-53.

Latrach-Tlemçani, L., Corroler, D., Barillier, D., Mosrati, R., 2008. Physiological states and energetic adaptation during growth of Pseudomonas putida mt-2 on glucose. Arch. Microbiol. 190, 141-150.

Lessie, T. G., Phibbs, P. V., 1984. Alternative pathways of carbohydrate utilization in pseudomonads. Annu. Rev. Microbiol. 38, 359-388.

Loeschcke, A., Markert, A., Wilhelm, S., Wirtz, A., Rosenau, F., Jaeger, K. E., Drepper, T., 2013. TREX: a universal tool for the transfer and expression of biosynthetic pathways in bacteria. ACS Synth. Biol. 2, 22-33.

Manoil, C., Beckwith, J., 1985. TnphoA: a transposon probe for protein export signals. Proc. Natl. Acad. Sci. USA. 82, 8129-8133.

Martínez-García, E., Aparicio, T., de Lorenzo, V., Nikel, P. I., 2017. Engineering Gram-negative microbial cell factories using transposon vectors. Methods Mol. Biol. 1498, 273-293.

Martínez-García, E., de Lorenzo, V., 2011. Engineering multiple genomic deletions in Gramnegative bacteria: analysis of the multi-resistant antibiotic profile of Pseudomonas putida KT2440. Environ. Microbiol. 13, 2702-2716.

Martínez-García, E., de Lorenzo, V., 2017. Molecular tools and emerging strategies for deep genetic/genomic refactoring of Pseudomonas. Curr. Opin. Biotechnol. 47, 120-132.

Martins dos Santos, V. A. P., Heim, S., Moore, E. R., Strätz, M., Timmis, K. N., 2004. Insights into the genomic basis of niche specificity of Pseudomonas putida KT2440. Environ. Microbiol. 6, 1264-1286.

Matsushita, K., Shinagawa, E., Ameyama, M., 1982. D-Gluconate dehydrogenase from bacteria, 2-keto-D-gluconate-yielding, membrane-bound. Methods Enzymol. 89, 187-193.

Matsushita, K., Toyama, H., Adachi, O., 1994. Respiratory chains and bioenergetics of acetic acid bacteria. Adv. Microb. Physiol. 36, 247-301.

Mclntire, W., Singer, T. P., Ameyama, M., Adachi, O., Matsushita, K., Shinagawa, E., 1985. Identification of the covalently bound flavins of D-gluconate dehydrogenases from 
Pseudomonas aeruginosa and Pseudomonas fluorescens and of 2-keto-D-gluconate dehydrogenase from Gluconobacter melanogenus. Biochem. J. 231, 651-654.

Miller, B. G., Raines, R. T., 2004. Identifying latent enzyme activities: substrate ambiguity within modern bacterial sugar kinases. Biochemistry. 43, 6387-6392.

Misawa, N., Nakagawa, M., Kobayashi, K., Yamano, S., Izawa, Y., Nakamura, K., Harashima, K., 1990. Elucidation of the Erwinia uredovora carotenoid biosynthetic pathway by functional analysis of gene products expressed in Escherichia coli. J. Bacteriol. 172, 6704-6712.

Nanchen, A., Fuhrer, T., Sauer, U., 2007. Determination of metabolic flux ratios from ${ }^{13} \mathrm{C}$ experiments and gas chromatography-mass spectrometry data: protocol and principles. Methods Mol. Biol. 358, 177-197.

Nelson, K. E., Weinel, C., Paulsen, I. T., Dodson, R. J., Hilbert, H., Martins dos Santos, V. A. P., Fouts, D. E., Gill, S. R., Pop, M., Holmes, M., Brinkac, L., Beanan, M., DeBoy, R. T., Daugherty, S., Kolonay, J., Madupu, R., Nelson, W., White, O., Peterson, J., Khouri, H., Hance, I., Chris Lee, P., Holtzapple, E., Scanlan, D., Tran, K., Moazzez, A., Utterback, T., Rizzo, M., Lee, K., Kosack, D., Moestl, D., Wedler, H., Lauber, J., Stjepandic, D., Hoheisel, J., Straetz, M., Heim, S., Kiewitz, C., Eisen, J. A., Timmis, K. N., Düsterhöft, A., Tümmler, B., Fraser, C. M., 2002. Complete genome sequence and comparative analysis of the metabolically versatile Pseudomonas putida KT2440. Environ. Microbiol. 4, 799808 .

Nikel, P. I., Chavarría, M., 2016. Quantitative physiology approaches to understand and optimize reducing power availability in environmental bacteria. In: McGenity, T. J., Timmis, K. N., Nogales-Fernández, B. (Eds.), Hydrocarbon and Lipid Microbiology Protocols-Synthetic and Systems Biology - Tools. Humana Press, Heidelberg, Germany, pp. 39-70.

Nikel, P. I., Chavarría, M., Danchin, A., de Lorenzo, V., 2016. From dirt to industrial applications: Pseudomonas putida as a Synthetic Biology chassis for hosting harsh biochemical reactions. Curr. Opin. Chem. Biol. 34, 20-29.

Nikel, P. I., Chavarría, M., Fuhrer, T., Sauer, U., de Lorenzo, V., 2015. Pseudomonas putida KT2440 strain metabolizes glucose through a cycle formed by enzymes of the EntnerDoudoroff, Embden-Meyerhof-Parnas, and pentose phosphate pathways. J. Biol. Chem. 290, 25920-25932. 
1 Nikel, P. I., de Lorenzo, V., 2013a. Implantation of unmarked regulatory and metabolic modules in Gram-negative bacteria with specialised mini-transposon delivery vectors. J. Biotechnol. $163,143-154$.

Nikel, P. I., de Lorenzo, V., 2013b. Engineering an anaerobic metabolic regime in Pseudomonas putida KT2440 for the anoxic biodegradation of 1,3-dichloroprop-1-ene. Metab. Eng. 15, 98-112.

Nikel, P. I., de Lorenzo, V., 2018. Pseudomonas putida as a functional chassis for industrial biocatalysis: From native biochemistry to trans-metabolism. Metab. Eng. 50, 142-155.

Nikel, P. I., Kim, J., de Lorenzo, V., 2014a. Metabolic and regulatory rearrangements underlying glycerol metabolism in Pseudomonas putida KT2440. Environ. Microbiol. 16, $239-254$.

Nikel, P. I., Martínez-García, E., de Lorenzo, V., 2014b. Biotechnological domestication of pseudomonads using synthetic biology. Nat. Rev. Microbiol. 12, 368-379.

Nikel, P. I., Pérez-Pantoja, D., de Lorenzo, V., 2013. Why are chlorinated pollutants so difficult to degrade aerobically? Redox stress limits 1,3-dichloroprop-1-ene metabolism by Pseudomonas pavonaceae. Philos. Trans. R. Soc. Lond. B Biol. Sci. 368, 20120377.

Nikel, P. I., Zhu, J., San, K. Y., Méndez, B. S., Bennett, G. N., 2009. Metabolic flux analysis of Escherichia coli creB and arcA mutants reveals shared control of carbon catabolism under microaerobic growth conditions. J. Bacteriol. 191, 5538-5548.

Nour-Eldin, H. H., Geu-Flores, F., Halkier, B. A., 2010. USER cloning and USER fusion: The ideal cloning techniques for small and big laboratories. Methods Mol. Biol. 643, 185-200.

Papagianni, M., 2012. Recent advances in engineering the central carbon metabolism of industrially important bacteria. Microb. Cell Fact. 11, 50.

Peekhaus, N., Conway, T., 1998. What's for dinner?: Entner-Doudoroff metabolism in Escherichia coli. J. Bacteriol. 180, 3495-3502.

Poblete-Castro, I., Wittmann, C., Nikel, P. I., 2019. Biochemistry, genetics, and biotechnology of glycerol utilization in Pseudomonas species. Microb. Biotechnol., In press, DOI: 10.1111/1751-7915.13400.

Ruiz, J. A., Fernández, R. O., Nikel, P. I., Méndez, B. S., Pettinari, M. J., 2006. dye (arc) Mutants: insights into an unexplained phenotype and its suppression by the synthesis of poly(3hydroxybutyrate) in Escherichia coli recombinants. FEMS Microbiol. Lett. 258, 55-60. 
1 Sánchez-Pascuala, A., de Lorenzo, V., Nikel, P. I., 2017. Refactoring the Embden-Meyerhof-

Parnas pathway as a whole of portable GlucoBricks for implantation of glycolytic modules in Gram-negative bacteria. ACS Synth. Biol. 6, 793-805.

Sánchez-Pascuala, A., Nikel, P. I., de Lorenzo, V., 2018. Re-factoring glycolytic genes for targeted engineering of catabolism in Gram-negative bacteria. In: Braman, J. C. (Ed.), Synthetic Biology: Methods and protocols. Springer New York, New York, NY, pp. 3-24.

Sandmann, G., 2015. Carotenoids of biotechnological importance. Adv. Biochem. Eng. Biotechnol. 148, 449-467.

Schweiggert, R. M., Carle, R., 2016. Carotenoid production by bacteria, microalgae, and fungi. In: Kaczor, A., Baranska, M. (Eds.), Carotenoids: Nutrition, analysis and technology. WileyBlackwell, Oxford, UK, pp. 217-240.

Silva-Rocha, R., Martínez-García, E., Calles, B., Chavarría, M., Arce-Rodríguez, A., de las Heras, A., Páez-Espino, A. D., Durante-Rodríguez, G., Kim, J., Nikel, P. I., Platero, R., de Lorenzo, V., 2013. The Standard European Vector Architecture (SEVA): a coherent platform for the analysis and deployment of complex prokaryotic phenotypes. Nucleic Acids Res. 41, D666-D675.

Sokatch, J. R., 1986. The biology of Pseudomonas. Academic Press, Boston, MS, USA.

Stutz, H., Bresgen, N., Eckl, P. M., 2015. Analytical tools for the analysis of $\beta$-carotene and its degradation products. Free Rad. Res. 49, 650-680.

Sudarsan, S., Dethlefsen, S., Blank, L. M., Siemann-Herzberg, M., Schmid, A., 2014. The functional structure of central carbon metabolism in Pseudomonas putida KT2440. Appl. Environ. Microbiol. 80, 5292-5303.

Szyperski, T., 1995. Biosynthetically directed fractional ${ }^{13} \mathrm{C}$-labeling of proteinogenic amino acids: An efficient analytical tool to investigate intermediary metabolism. Eur. J. Biochem. 232, 433-448.

Vallenet, D., Calteau, A., Cruveiller, S., Gachet, M., Lajus, A., Josso, A., Mercier, J., Renaux, A., Rollin, J., Rouy, Z., Roche, D., Scarpelli, C., Médigue, C., 2017. MicroScope in 2017: an expanding and evolving integrated resource for community expertise of microbial genomes. Nucleic Acids Res. 45, D517-D528. 
van Belkum, A., Struelens, M., de Visser, A., Verbrugh, H., Tibayrenc, M., 2001. Role of genomic typing in taxonomy, evolutionary genetics, and microbial epidemiology. Clin. Microbiol. Rev. 14, 547-560.

van den Bergh, B., Swings, T., Fauvart, M., Michiels, J., 2018. Experimental design, population dynamics, and diversity in microbial experimental evolution. Microbiol. Mol. Biol. Rev. 82.

van der Werf, M. J., Overkamp, K. M., Muilwijk, B., Koek, M. M., van der Werff-van der Vat, B. J., Jellema, R. H., Coulier, L., Hankemeier, T., 2008. Comprehensive analysis of the metabolome of Pseudomonas putida S12 grown on different carbon sources. Mol. BioSyst. 4, 315-327.

Vicente, M., Cánovas, J. L., 1973a. Regulation of the glucolytic enzymes in Pseudomonas putida. Arch. Microbiol. 93, 53-64.

Vicente, M., Cánovas, J. L., 1973b. Glucolysis in Pseudomonas putida: physiological role of alternative routes from the analysis of defective mutants. J. Bacteriol. 116, 908-914.

Wang, Q., Xu, J., Sun, Z., Luan, Y., Li, Y., Wang, J., Liang, Q., Qi, Q., 2019. Engineering an in vivo EP-bifido pathway in Escherichia coli for high-yield acetyl-CoA generation with low $\mathrm{CO}_{2}$ emission. Metab. Eng. 51, 79-87.

Wilkes, R. A., Mendonca, C. M., Aristilde, L., 2018. A cyclic metabolic network in Pseudomonas protegens Pf-5 prioritizes the Entner-Doudoroff pathway and exhibits substrate hierarchy during carbohydrate co-utilization. Appl. Environ. Microbiol. 85, e02084-18.

Winsor, G. L., Griffiths, E. J., Lo, R., Dhillon, B. K., Shay, J. A., Brinkman, F. S., 2016. Enhanced annotations and features for comparing thousands of Pseudomonas genomes in the Pseudomonas Genome Database. Nucleic Acids Res. 44, D646-D653.

Wirth, N. T., Kozaeva, E., Nikel, P. I., 2019. Accelerated genome engineering of Pseudomonas putida by I-Scel-mediated recombination and CRISPR-Cas9 counterselection. Microb. Biotechnol., In press, DOI: 10.1111/1751-7915.13396.

Worsey, M. J., Williams, P. A., 1975. Metabolism of toluene and xylenes by Pseudomonas putida (arvilla) mt-2: evidence for a new function of the TOL plasmid. J. Bacteriol. 124, 7-13.

Yu, S., Lai, B., Plan, M. R., Hodson, M. P., Lestari, E. A., Song, H., Krömer, J. O., 2018. Improved performance of Pseudomonas putida in a bioelectrochemical system through overexpression of periplasmic glucose dehydrogenase. Biotechnol. Bioeng. 115, 145155. 
1 Zhao, J., Li, Q., Sun, T., Zhu, X., Xu, H., Tang, J., Zhang, X., Ma, Y., 2013. Engineering central metabolic modules of Escherichia coli for improving $\beta$-carotene production. Metab. Eng. $17,42-50$.

4 
Table 1. Bacterial strains used in this study.

\begin{tabular}{|c|c|c|}
\hline Strain & Relevant characteristics ${ }^{a}$ & $\begin{array}{r}\text { Reference or } \\
\text { source }\end{array}$ \\
\hline \multicolumn{3}{|l|}{ Escherichia coli } \\
\hline \multirow[t]{2}{*}{ CC118 } & Cloning host; $\Delta$ (ara-leu) araD $\Delta / a c X 174$ galE galK phoA & Manoil and \\
\hline & thiE1 rpsE rpoB(RifR) argE(Am) recA1 & Beckwith (1985) \\
\hline \multirow[t]{3}{*}{$\mathrm{DH} 5 \alpha \lambda$ pir } & Cloning host; $\mathrm{F}^{-} \lambda^{-}$endA1 gInX44(AS) thiE1 recA1 relA1 & Hanahan and \\
\hline & spoT1 gyrA96(NalR) rfbC1 deoR nupG $\Phi 80(l a c Z \Delta M 15)$ & Meselson (1983) \\
\hline & $\Delta(\arg F-l a c) \cup 169 h s d R 17\left(r_{K}-m_{K}^{+}\right), \lambda$ pir lysogen & \\
\hline \multirow[t]{2}{*}{ BW25113b } & Wild-type $\quad$ strain; $\quad \mathrm{F}^{-} \quad \lambda^{-} \quad \Delta(\operatorname{araD}$-araB $) 567$ & Datsenko and \\
\hline & $\Delta / a c Z 4787(:: r r n B-3) r p h-1 \Delta(r h a D-r h a B) 568$ hsdR514 & Wanner (2000) \\
\hline \multirow[t]{2}{*}{ BPfkAB } & Same as BW25113, but $\triangle p f k A 775:: F R T \Delta p f k B 722:: a p h A ;$ & Sánchez-Pascuala \\
\hline & $\mathrm{Km}^{\mathrm{R}}$ & et al. (2017) \\
\hline \multirow[t]{2}{*}{ BPG } & Same as BW25113, but $\Delta g / k-726:: F R T \Delta p t s / 745:: a p h A ;$ & Nikel and de \\
\hline & $\mathrm{Km}^{\mathrm{R}}$ & Lorenzo (2013a) \\
\hline \multicolumn{3}{|c|}{ Pseudomonas putida } \\
\hline \multirow[t]{2}{*}{ KT2440 } & Wild-type strain, derived from P. putida mt-2 (Worsey and & Bagdasarian et al. \\
\hline & Williams, 1975) cured of the TOL plasmid pWW0 & $(1981)$ \\
\hline KT2440 $\Delta g / k$ & $\begin{array}{l}\text { Same as KT2440, but with an in-frame deletion of the glk } \\
\text { gene (PP_1011) }\end{array}$ & $\begin{array}{r}\text { Sánchez-Pascuala } \\
\text { et al. (2017) }\end{array}$ \\
\hline KT2440 $\Delta g c d$ & $\begin{array}{l}\text { Same as KT2440, but with an in-frame deletion of the gcd } \\
\text { gene (PP_1444) }\end{array}$ & This study \\
\hline $\begin{array}{l}\mathrm{KT} 2440 \\
\quad \triangle P P \_3382-4\end{array}$ & $\begin{array}{l}\text { Same as KT2440, but with an in-frame deletion of the } \\
\text { genes PP_3382, PP_3383 and PP_3384 by a single } \\
\text { deletion event }\end{array}$ & This study \\
\hline $\begin{array}{l}\mathrm{KT} 2440 \\
\quad \Delta P P \_3623\end{array}$ & $\begin{array}{l}\text { Same as KT2440, but with an in-frame deletion of the } \\
\text { PP_3623 gene }\end{array}$ & This study \\
\hline KT2440 & Same as KT2440, but with an in-frame deletion of the & This study \\
\hline
\end{tabular}




\begin{tabular}{cll}
\hline$\Delta P P_{-} 4232$ & $P P_{-} 4232$ gene & \\
KT2440 $\Delta$ gad & Same as KT2440 $\Delta P P_{-} 3382-4$, but with an in-frame & This study \\
& deletion of the genes $P P_{-} 3623$ and $P_{-} 4232$ & \\
KT2440 $\Delta$ edd & Same as KT2440, but with an in-frame deletion of the edd & This study \\
& gene $\left(P P_{-} 1010\right)$ & \\
GC1 & Glycolytic chassis l; derivative of $P$. putida KT2440 with \\
& the deletions described for the mutants $\Delta g l k, \Delta g c d, \Delta g a d$ & This study \\
& and $\Delta$ edd & \\
\hline
\end{tabular}

2 a Antibiotic markers: $\mathrm{Km}$, kanamycin; Nal, nalidixic acid; and Rif, rifampicin.

3 b Strain obtained from the E. coli Genetic Stock Center (Yale University, New Haven, CT, 4 USA). 
1 Table 2. Metabolomic determinations ${ }^{a}$ in wild-type and engineered $P$. putida strains grown in 2 glucose cultures.

3

P. putida strain/plasmid
Intracellular content $\left(\mathrm{nmol} \mathrm{mgcDW}{ }^{-1}\right)$ of

\begin{tabular}{lccccc} 
& Glucose-6- $P$ & Fructose-6- $P$ & Dihydroxyacetone- $P$ & Glyceraldehyde-3- $P$ & Pyruvate \\
\hline KT2440/pSEVA224 (empty vector) & $52 \pm 9^{b}$ & $3.8 \pm 0.2$ & $1.4 \pm 0.2$ & $0.39 \pm 0.08^{b}$ & $1.1 \pm 0.4$ \\
GC1/pS224-GBI (Module I) & $73 \pm 6$ & $5.4 \pm 0.2$ & $2.2 \pm 0.3$ & $0.85 \pm 0.05$ & $3.1 \pm 0.5$ \\
\hline
\end{tabular}

4

5 a Cells were grown aerobically in M9 minimal medium added with glucose at $20 \mathrm{mM}$ as the

6 sole carbon source and IPTG at $1 \mathrm{mM}$, harvested during exponential growth, and rapidly

7 quenched with liquid $\mathrm{N}_{2}$. Intracellular metabolites were extracted and their concentration

8 determined by means of liquid chromatography coupled to mass spectrometry. Each

9 parameter is reported as the mean value \pm standard deviation from duplicate measurements

10 in at least two independent experiments. CDW, cell dry weight.

11 b Values obtained from Sánchez-Pascuala et al. (2017). 


\section{FIGURES}

3 Figure 1 - Predominant glycolytic regimes in bacterial species and engineering

4 strategies. (a) Glucose catabolism occurs mainly through the activity of the Embden-Meyerhof-

5 Parnas (EMP) or the Entner-Doudoroff (ED) pathway, which differ both in the metabolic

6 architecture of the route and the ATP yield on substrate (Flamholz et al., 2013; Nikel et al., 2016).

7 The abbreviations used in this diagram are as follows: G6P, glucose-6-P; FBP, fructose-1,6- $P_{2}$;

8 KDPG, 2-keto-3-deoxy-6-phosphogluconate; GA3P, glyceraldehyde-3-P; Pyr, pyruvate; and $\mathrm{P}_{\mathrm{i}}$,

9 inorganic phosphate. Note that some reactions have been lumped for the sake of simplicity. (b)

10 Schematic representation of GlucoBricks, a synthetic biology platform for engineering glycolysis

11 in Gram-negative bacteria (Sánchez-Pascuala et al., 2017). In plasmid pS224·GBI, the glycolytic

12 genes encoding the enzymes of the preparatory phase of the EMP pathway (i.e. module I) are

13 placed under the transcriptional control of an inducible LaclQ/P $/ \mathrm{P}_{\text {trc }}$ element as a single

14 transcriptional unit flanked by Avrll and BamHI restriction sites. Each gene is preceded by a

15 synthetic regulatory element, indicated by a purple circle, composed of a ribosome binding site

16 and a short spacer sequence (5'-AGG AGG AAA AAC AT-3'). 
1 Figure 2 2 Schematic representation of the central carbon metabolism in P. putida

2 KT2440. Glucose catabolism in this species occurs mainly through the activity of the Entner-

3 Doudoroff (ED) pathway, and part of the trioses- $P$ thereby generated are recycled back to

4 hexoses- $P$ by means of the EDEMP cycle (shaded in blue), that also encompasses activities from 5 the Embden-Meyerhof-Parnas (EMP) and pentose phosphate (PP) pathways. Note that a set of 6 peripheral reactions can also oxidize glucose to gluconate and/or 2-ketogluconate (2KG) before 7 any phosphorylation of the intermediates occurs. Each metabolism block is indicated with a 8 different color, and catabolism downward acetyl-coenzyme A ( $\mathrm{COA})$ is indicated by a wide gray 9 arrow. Note that 6-phosphofructo-1-kinase (Pfk) activity is absent in the network, as indicated as 10 a dashed grey row close to the gluconeogenic Fbp reaction. The abbreviations used in this 11 diagram are as follows: G6P, glucose-6-P; F6P, fructose-6-P; FBP, fructose-1,6- $P_{2}$; DHAP, 12 dihydroxyacetone-P; GA3P, glyceraldehyde-3-P; BPG, glycerate-1,3-P2; 3PG, glycerate-3-P; 13 2PG, glycerate-2-P; PEP, phosphoenolpyruvate; Pyr, pyruvate; 6PG, 6-phosphogluconate; 14 KDPG, 2-keto-3-deoxy-6-phosphogluconate; 2K6PG, 2-ketogluconate-6-P; OM, outer membrane; 15 PS, periplasmic space; and IM, inner membrane. 
1 Figure 3 - Phenotypic characterization of the glk and gcd deletion in P. putida KT2440. (a)

2 In vitro quantification of the specific (Sp) glucokinase (GIk) and glucose dehydrogenase (Gcd)

3 activity in wild-type (WT) P. putida KT2440, and its $\Delta g / k$ and $\Delta g c d$ mutant derivatives. All strains

4 were grown on M9 minimal medium added with glucose at $20 \mathrm{mM}$ and cells were harvested in

5 mid-exponential phase to obtain cell-free extracts. Each bar represents the mean value of the

6 corresponding enzyme activity \pm standard deviation of quadruplicate measurements from at least

7 two independent experiments. Significant differences $(P<0.05$, as evaluated by means of the

8 Student's $t$ test) in the pair-wise comparison of a given recombinant to the control WT strain are

9 indicated by an asterisk. (b) Growth curves of $P$. putida KT2440 and its $\Delta g / k$ and $\Delta g c d$ derivative

10 under glycolytic (M9 minimal medium with glucose) or gluconeogenic (M9 minimal medium with

11 succinate) conditions. Each data point represents the mean value of the optical density measured

12 at $600 \mathrm{~nm}\left(\mathrm{OD}_{600}\right)$ of quadruplicate measurements from at least three independent experiments.

13 The specific growth rates $(\mu)$ were calculated from these data during exponential growth, and the 14 inset shows the mean values \pm standard deviations for each strain. The abbreviations used in this 15 diagram are as follows: G6P, glucose-6-P; and PQQ, (redox cofactor) pyrroloquinoline quinone. 
1 Figure 4 - Phenotypic characterization of the gad deletions in P. putida KT2440. (a)

2 Distribution of hypothetical genes in the chromosome of $P$. putida KT2440 encoding gluconate 2-

3 dehydrogenase ( $\mathrm{Gad}$ ) activity. The relative orientation of the genes in the chromosome is likewise

4 indicated. FAD, flavin adenine dinucleotide. (b) In vitro quantification of the specific (Sp) Gad

5 activity in wild-type (WT) $P$. putida KT2440, and the mutant strains $\triangle P P$ 3382-4 (which

6 comprises the deletions of PP_3382, PP_3383, and PP_3384), $\triangle P P \_3623, \Delta P P \_4232$, and

$7 \Delta$ gad (which comprises the deletions from $\triangle P P \_3382-4, \Delta P P_{-} 3623$, and $\triangle P P \_4232$ ). All strains

8 were grown on $\mathrm{M9}$ minimal medium added with glucose at $20 \mathrm{mM}$ and cells were harvested in

9 mid-exponential phase to obtain cell-free extracts. Each bar represents the mean value of the

10 corresponding enzyme activity \pm standard deviation of quadruplicate measurements from at least

11 two independent experiments. Significant differences $(P<0.05$, as evaluated by means of the

12 Student's $t$ test) in the pair-wise comparison of a given recombinant to the control WT strain are

13 indicated by an asterisk. (c) Growth curves of $P$. putida KT2440 and gad mutants under glycolytic 14 (M9 minimal medium with glucose) or gluconeogenic (M9 minimal medium with succinate) 15 conditions. Each data point represents the mean value of the optical density measured at $600 \mathrm{~nm}$ $16\left(\mathrm{OD}_{600}\right)$ of quadruplicate measurements from at least three independent experiments. The 17 specific growth rates $(\mu)$ were calculated from these data during exponential growth, and the inset 18 shows the mean values \pm standard deviations for each strain. 
1 Figure 5 - Growth phenotype characterization of different glucose catabolism mutants of

2 P. putida KT2440. M9 minimal medium plates, containing either $20 \mathrm{mM}$ glucose (left plate) or 30

3 mM succinate (right plate), were seeded with P. putida KT2440 (wild-type) and the mutants $\Delta g / k$

4 (PP_1011, glucokinase), $\Delta g c d$ (PP_1444, glucose dehydrogenase), $\Delta g / k \Delta g c d, \Delta$ gad (which 5 comprises the deletions of $\triangle P P \_3382, \triangle P P \_3383, \triangle P P \_3384, \triangle P P \_3623$ and $\triangle P P \_4232$,

6 encoding gluconate 2-dehydrogenase), and $\Delta$ edd (PP_1010, 6-phosphogluconate dehydratase),

7 and incubated for $36 \mathrm{~h}$ at $30^{\circ} \mathrm{C}$. The phenotypes of the strains are indicated as "+" (growth) and

8 "-" (no growth). The values in parentheses indicate the normalized growth coefficient, which

9 represents the fraction of the specific growth rate attained by the mutant strain when compared to

10 that of the wild-type under the same culture conditions. Significant differences $(P<0.05$, as

11 evaluated by means of the Student's $t$ test) in the comparison of the normalized growth coefficient

12 between a given mutant and $P$. putida KT2440 are indicated in red. 
1 Figure 6 - Engineering a EMP-based glycolytic route in P. putida GC1. (a) Simplified 2 representation of central carbon metabolism in P. putida GC1 (glycolytic chassis I) upon 3 implantation of the synthetic glycolysis. The metabolic activities eliminated in this strain are 4 represented by dashed red arrows, the biochemical reactions encoded by the genes within 5 Module I of the GlucoBrick platform are indicated in purple, and endogenous reactions are shown 6 in gray. Reactions converting GA3P into pyruvate are lumped. The abbreviations used in this 7 diagram are as indicated in Fig. 2. (b) M9 minimal medium plates, containing either $20 \mathrm{mM}$ 8 glucose (left column) or $30 \mathrm{mM}$ succinate (right column), were inoculated with $P$. putida KT2440 9 (WT) carrying the empty pSEVA224 vector, and P. putida GC1 carrying either the empty 10 pSEVA224 vector or GlucoBrick Module I (pS224 GBI, see also Fig. 1b) and incubated for $36 \mathrm{~h}$ at $1130^{\circ} \mathrm{C}$. Culture medium additives (Km, kanamycin; and IPTG, isopropyl-1-thio- $\beta$ 12 galactopyranoside) are likewise indicated. (c) Growth curves of $P$. putida KT2440 carrying the 13 empty pSEVA224 vector, and P. putida GC1 carrying plasmid pS224 GBI on M9 minimal medium 14 with $20 \mathrm{mM}$ glucose, $50 \mu \mathrm{g} \mathrm{ml}^{-1} \mathrm{Km}$, and $1 \mathrm{mM} \mathrm{IPTG}$ in microtiter-plate cultures. Each data point 15 in the growth curves represents the mean value of the optical density measured at $600 \mathrm{~nm}$ $16\left(\mathrm{OD}_{600}\right)$ in quadruplicate measurements from at least three independent experiments. The 17 specific growth rates $(\mu)$ were calculated from these data during exponential growth, and the inset 18 shows the mean value \pm standard deviations for each strain. 
1 Figure 7 - Physiological and biochemical characterization of the designed EMP glycolytic

2 device in P. putida GC1. (a) In vitro quantification of the specific (Sp) glucokinase (Glk) activity

3 in wild-type (WT) E. coli BW25113 and its $\Delta g / k \Delta$ pts/ derivative, and in P. putida KT2440 (WT)

4 and its $\Delta g / k$ derivative (left panel) carrying the empty pSEVA224 vector. The right panel shows

5 the Glk activity measurements in P. putida GC1 carrying plasmid pS224.GBI. (b) In vitro

6 quantification of the Sp 6-phosphofructo-1-kinase (Pfk) activity in WT E. coli BW25113 and its

$7 \quad \Delta p f k A \Delta p k f B$ derivative (termed $\Delta p f k$ ), and in P. putida KT2440 (WT, left panel) carrying the

8 empty pSEVA224 vector. The right panel shows the Pfk activity for $P$. putida GC1 carrying

9 plasmid pS224.GBI. (c) Glucose consumption profiles of $P$. putida KT2440 and GC1 carrying

10 either the control vector (pSEVA224) or pS224.GBI. All strains were grown on M9 minimal

11 medium with $20 \mathrm{mM}$ glucose, $50 \mu \mathrm{g} \mathrm{ml}^{-1} \mathrm{Km}$, and $1 \mathrm{mM}$ IPTG, and cells were harvested in mid-

12 exponential phase to obtain cell-free extracts and cell dry weight (CDW). Note that $P$. putida

13 GC1/pS224.GBI was compared to P. putida $\Delta$ glk for Glk activity, and to P. putida KT2440 for Pfk

14 activity. Each bar represents the mean value of the corresponding parameter \pm standard

15 deviation of quadruplicate measurements from at least two independent experiments. Significant

16 differences ( $P<0.05$, as evaluated by means of the Student's $t$ test) in the pair-wise comparison

17 of a given recombinant to the control strain are indicated by an asterisk. 
1 Figure 8 - Assessment of the metabolic origin of glycolytic intermediates in engineered

2 P. putida using ${ }^{13}$-labelled substrates. (a) Glucose-6- $P$, a hub metabolite in the upper 3 metabolism of $P$. putida, can be transformed into pyruvate (Pyr) by means of the Entner4 Doudoroff (ED), Embden-Meyerhof-Parnas (EMP), or pentose phosphate (PP) pathways. The 5 expected labelling pattern of individual Pyr molecules is indicated for each processing route. (b) 6 Positional ${ }^{13} \mathrm{C}$ enrichment of trioses enables tracing the metabolic origin of the Pyr pool. P. putida 7 KT2440 (WT) carrying the empty pSEVA224 vector and P. putida GC1 carrying plasmid 8 pS224.GBI were grown on M9 minimal medium with $20 \mathrm{mM}\left[{ }^{1-13} \mathrm{C}_{1}\right]$-glucose, and the biomass 9 was harvested in mid-exponential phase to process samples for GC-MS analysis. (c) In vitro 10 quantification of the specific (Sp) 6-phoshogluconate (6PG) dehydratase activity (Edd), first step 11 of the ED pathway [6-phosphogluconate (6PG) $\rightarrow$ 2-keto-3-deoxy-6-phosphogluconate (KDPG)], 12 in P. putida KT2440 (WT) and GC1. KDPG aldolase (Eda) subsequently splits KDPG into 13 glyceraldehyde-3-P (GA3P) and Pyr. Strains were grown on M9 minimal medium with $20 \mathrm{mM}$ 14 glucose and cells were harvested in mid-exponential phase to obtain cell-free extracts. Each bar 15 represents the mean Edd activity value \pm standard deviation of quadruplicate measurements from 16 at least two independent experiments. Significant differences $(P<0.01$, as evaluated by means of 17 the Student's $t$ test) in the pair-wise comparison are indicated by an asterisk. 
1 Figure 9 - Engineered $P$. putida strains running a synthetic glycolysis display enhanced

2 carotenoid synthesis from glucose. (a) Scheme of the crt gene cluster from Pantoea ananatis,

3 expressed from a XyIS/Pm regulatory element in plasmid pS1.CRT. RBS, ribosome binding site.

4 (b) Carotenoid synthesis pathway. The key intermediate FPP is transformed into $\beta$-carotene via

5 the MEP pathway and the heterologous carotenoid pathway, which includes the sequential action

6 of the CrtE, CrtB, Crtl, and CrtY components. The abbreviations used in this diagram are as

7 follows: GA3P, glyceraldehyde-3-P; HMBPP, 4-hydroxy-3-methylbut-2-enyl pyrophosphate; IPP,

8 isopentenyl pyrophosphate; DMAPP, dimethylallyl pyrophosphate; FPP, farnesyl pyrophosphate;

9 GGPP, geranylgeranyl pyrophosphate; and MEP pathway, methylerythritol 4-phosphate pathway.

10 Note that the number of carbon atoms in each metabolite is given in parentheses, and dashed

11 lines represent multiple biochemical steps. (c) Analysis of carotenoid synthesis in wild-type and 12 engineered $P$. putida cells. Wild-type (WT) strain KT2440 and P. putida GC1, containing Module I 13 of the GlucoBrick platform (GBI), were transformed either with an empty pPS1 vector or plasmid 14 pPS1.CRT (carrying the crt genes). All the resulting engineered strains were grown on M9 15 minimal medium with $20 \mathrm{mM}$ glucose (and antibiotics and inducers as appropriate), and cells 16 were harvested 24-h post-induction of the expression of genes encoding the carotenoid pathway.

17 The carotenoid content, glucose consumption, and cell dry weight (CDW) concentration were 18 analyzed in all the samples, and the mass yield of carotenoid on sugar ( $\left.Y_{\text {carotenoidglucose }}\right)$ was 19 calculated from these values. A representative picture of the engineered strains, plated on M9 20 minimal medium containing glucose and incubated at $30^{\circ} \mathrm{C}$ for $48 \mathrm{~h}$, is shown at the bottom of the 21 figure. Bars represent mean values \pm standard deviation of triplicate measurements from at least 22 two independent experiments. Significant differences $(P<0.05$, as evaluated by means of the 23 Student's $t$ test) in pair-wise comparisons are indicated by an asterisk. N.D., not detected (i.e. 24 control experiments, in which the corresponding strains carry an empty pPS1 vector). 


\section{a}

b

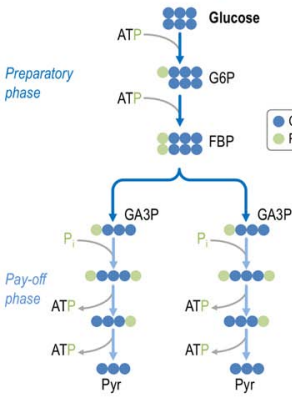

Energy yield $=2$ ATP
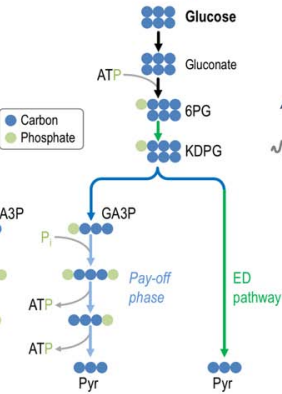

Energy yield $=1 \mathrm{ATP}$
EMP pathway

Preparatory phase
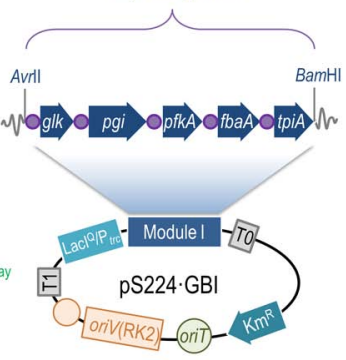

- Synthetic RBS 


\section{Glucose Gluconate 2KG}

\section{$\mathrm{OM}$}

PS

IM

Deletions implemented in this work

- ED pathway

- EMP pathway

- PP pathway

- Peripheral reactions
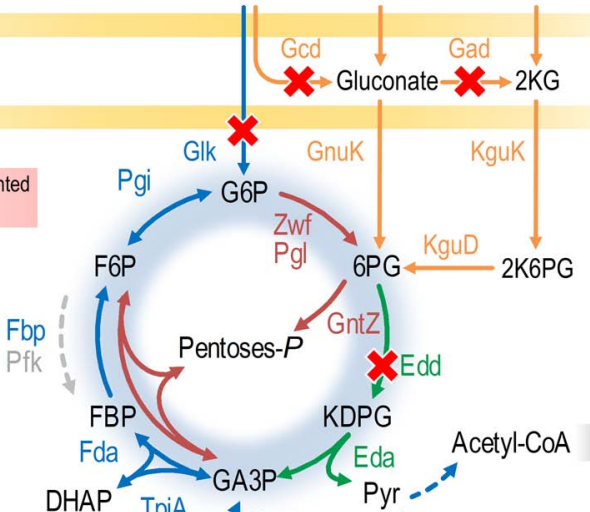

TpiA

$\downarrow$ Pyk

Pgk 
a Gluconate $\underset{\longrightarrow}{\longrightarrow}$ 2-Ketogluconate

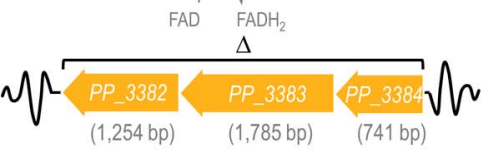

$\sqrt{\frac{\Delta}{P P \_3623}} \sqrt{(1,344 \mathrm{bp})} \frac{\Delta}{\sqrt{\frac{P P_{-} 4232}{(1,212 \mathrm{bp})}}} \mathrm{N}$
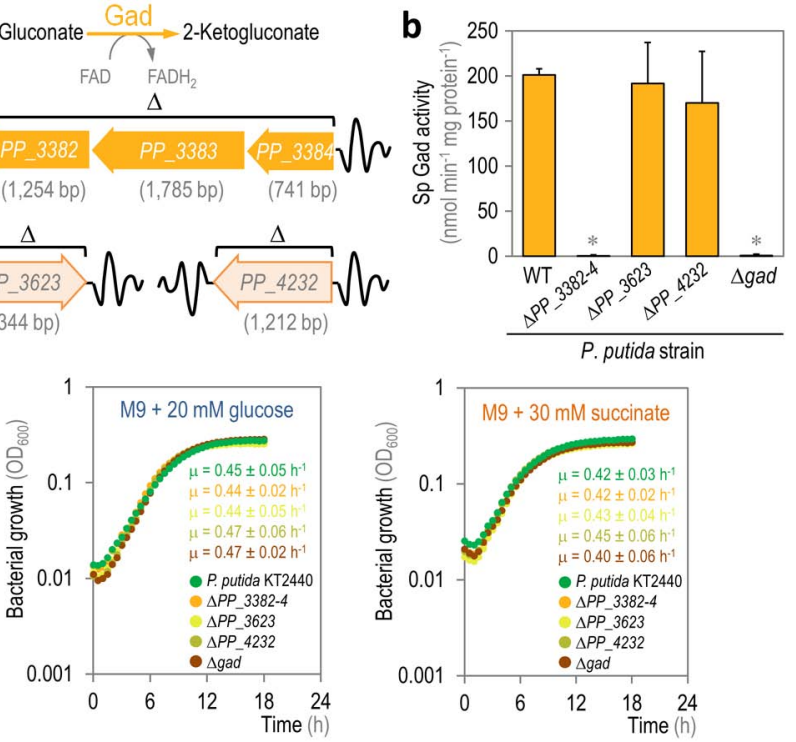


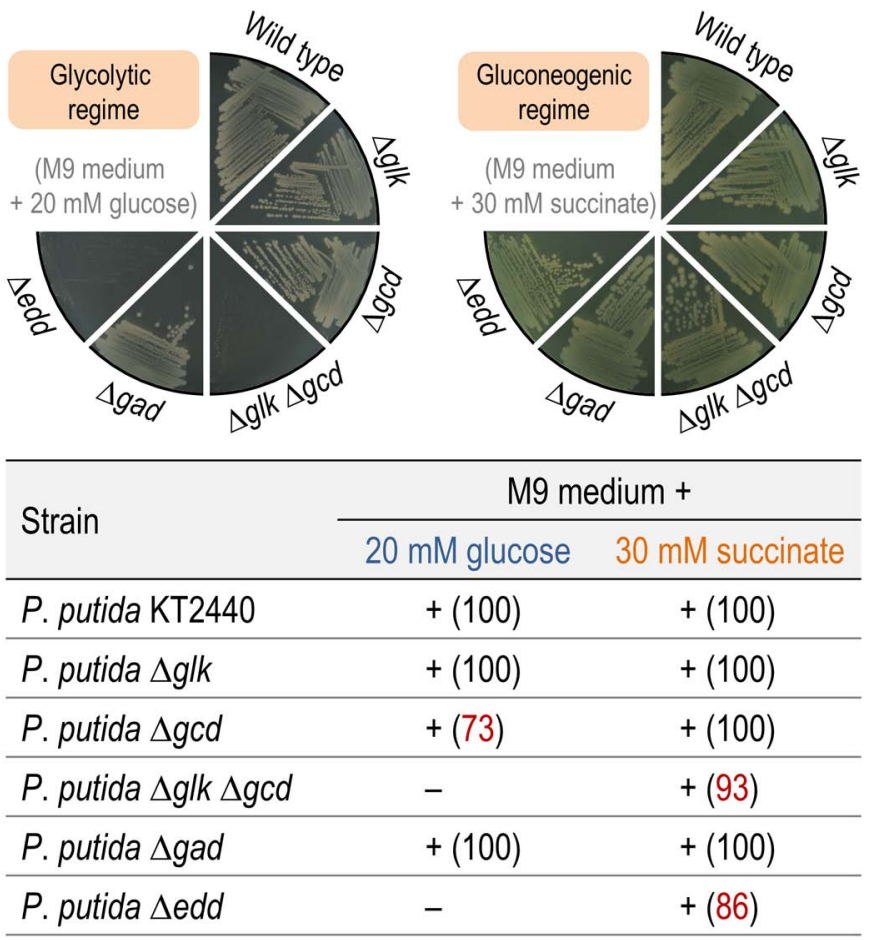


${ }^{12} \mathrm{C}$
${ }^{13} \mathrm{C}$

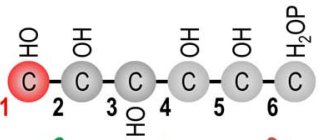

ED pathway

EMP pathway

PP pathway

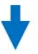

1 C $00^{-}$

4 C 00-

$1 \mathrm{C} \mathrm{OO}^{-}$

4 C $0^{-}$

${ }^{1} \mathrm{C} \mathrm{OO}^{-}{ }^{4} \mathrm{C} \mathrm{OO}^{-}$ $2 \mathrm{C} \mathrm{O}+$

$5 \mathrm{C} 0$

${ }^{3} \mathrm{C} \mathrm{H}_{3}$

$6 \mathrm{C}_{3}$

$2 \mathrm{Co}+$

$5 \mathrm{C}$

${ }^{3} \mathrm{C} \mathrm{H}_{3}$
$6 \mathrm{C}_{3}$
$2 \frac{1}{C} 0+5 \frac{1}{C} 0$

$3 \mathrm{C}_{3}$
$6 \frac{\mathrm{C}}{\mathrm{C}} \mathrm{H}_{3}$

\section{b}
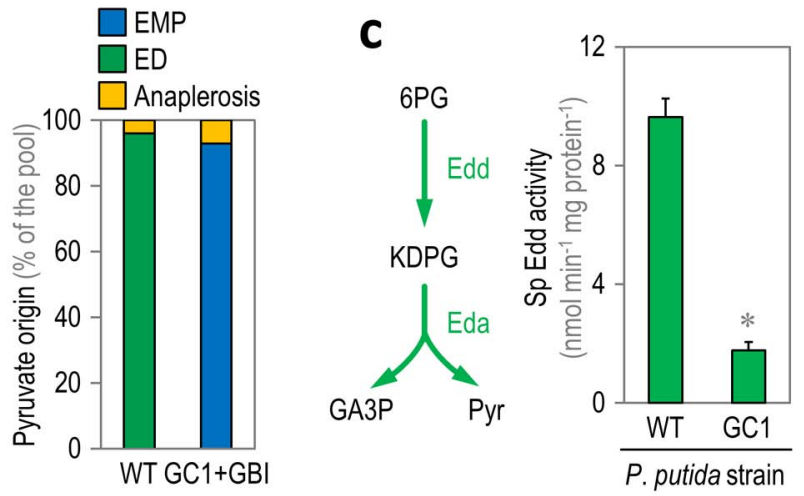
Pm

$\longrightarrow \quad$ synthase

a $W \cdot \operatorname{crtE} \cdot \operatorname{crtB}$

Geranylgeranyl

diphosphate synthase

From synthetic glycolysis

Pyruvate (C3) + GA3P (C3)

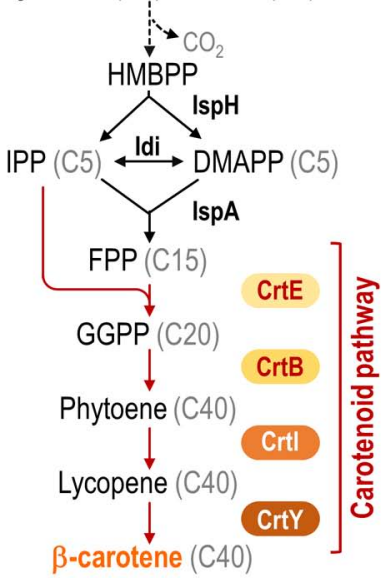

b
Lycopene

cyclase

Phytoene

desaturase

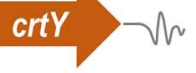

$1 \mathrm{~kb}$

Synthetic RBS 


\title{
Supplementary Material
}

\section{Functional implementation of a linear glycolysis for sugar catabolism in Pseudomonas putida}

\author{
by \\ Alberto Sánchez-Pascuala, Lorena Fernández-Cabezón, Víctor de Lorenzo, and Pablo I. Nikel

\section{SUPPLEMENTARY METHODS}

Construction of mutant Pseudomonas putida strains. Clean P. putida knock-out mutants were obtained following the protocol described by Martínez-García and de Lorenzo (2011). The method is based on the use of the suicide $p E M G$ vector (Table S1), containing flanking regions upstream and downstream of the target gene(s) amplified by PCR using chromosomal DNA from strain KT2440 as the template. The oligonucleotides employed to amplify these ca. 500bp long flanking regions (termed TS1, upstream; and TS2, downstream) are listed in Table S2. A 1-kbp amplification product (i.e. spanning the TS1-TS2 regions that flank the target gene or group of genes, indicated with " $x$ " in the primer names) were obtained using the two individual 500-bp amplicons as the template and external oligonucleotides (i.e. $x$-TS1F and $x$-TS2R) by splicing-by-overlap extension (SOEing) PCR (Horton, 1995; Nikel and de Lorenzo, 2013). The TS1-TS2 DNA modules were digested with EcoRI and BamHI (except for the cases indicated in Table S2), cloned into the I-Scel-bearing pEMG vector digested with the same enzymes [giving rise to plasmid(s) pEMG $\Delta x$, Table S1] and verified by enzyme restriction and DNA sequencing. The resulting pEMG $\Delta x$ vectors were electroporated in P. putida KT2440 (and derivatives thereof) to force cointegration events (as pEMG-derived plasmids lack a compatible origin of replication for Pseudomonas species). Merodiploids were selected by plating bacteria in lysogeny broth (LB) medium plates containing kanamycin (Km) and individual clones were checked by PCR using oligonucleotides $x$-TS1F and $x$-TS2R. Once a suitable cointegration event was obtained, the selected bacterial clone was transformed with plasmid pSW-I and selected in LB medium plates containing ampicillin (Ap). In order to facilitate the recombination process (mediated by the I-Scel endonuclease) that allows for the deletion event, the strains were incubated for $6 \mathrm{~h}$ in $5 \mathrm{ml}$ of LB medium containing $500 \mu \mathrm{g} \mathrm{ml}^{-1} \mathrm{Ap}$ and $15 \mathrm{mM}$ sodium 3methylbenzonate (3-mBz). The resulting cultures were plated onto LB medium plates to obtain individual colonies, which were re-streaked onto LB medium with or without $\mathrm{Km}$ to check for the loss of the cointegrated plasmid. Km-sensitive clones were analyzed by colony PCR (using the pair of oligonucleotides $x$-TS1F and $x$-TS2R) to distinguish between events leading to either deletion of the intended region or revertant [i.e. wild-type genotype]. As a final step, the pSW-I plasmid was eliminated from the strains after several consecutive passes in liquid LB medium. In order to verify the elimination of plasmid pSW-I, all the candidates were plated onto LB medium plates with $500 \mu \mathrm{g} \mathrm{ml}^{-1} \mathrm{Ap}$ and checked by PCR using the oligonucleotides pSW-F and pSW-R. 
Preparation of bacterial cell-free extracts. Cell-free extracts of Escherichia coli and $P$. putida were obtained by a modification of published protocols (Chavarría et al., 2016; Nikel et al., 2014). Enzyme activity determinations were carried out in cell-free extracts obtained from bacterial cultures harvested during the mid-exponential phase of growth [i.e. corresponding to an optical density measured at $600 \mathrm{~nm}\left(\mathrm{OD}_{600}\right)$ of ca. 0.5$]$. Cell-free extracts were obtained from $50 \mathrm{ml}$ of culture broth (in 250-ml Erlenmeyer flasks). Biomass was collected by centrifuging the cultures at 4,000 r.p.m. for $15 \mathrm{~min}$ at $4^{\circ} \mathrm{C}$. Cell pellets were washed twice with $25 \mathrm{ml}$ of precooled $67 \mathrm{mM}$ potassium phosphate buffer $(\mathrm{pH}=7.1)$ at $4^{\circ} \mathrm{C}$. From this step onwards, the protocol followed to obtain cell-free extracts was modified depending on the location of the enzyme (i.e. membrane-bound or cytoplasm). For enzymes located in or associated with the cell membrane (e.g. Gcd and Gad), the resulting pellets were suspended in 2-ml Eppendorf tubes with the appropriate volume of pre-cooled $60 \mathrm{mM}$ glycylglycine buffer $(\mathrm{pH}=7.1)$ to obtain a cell density of $0.2 \mathrm{~g}$ of cells (wet weight) per milliliter of buffer. The suspensions were sonicated in seven 30 -s intervals separated by 1.5 min rests in ice to avoid heating of the sample (18-20 $\mathrm{kHz}, 1.0-1.5 \mathrm{~A}$ ). At this point, the mixtures were centrifuged at 13,000 r.p.m. for $30 \mathrm{~min}$ at $4^{\circ} \mathrm{C}$ to remove insoluble cell debris. The cell-free extracts were stored at $-20^{\circ} \mathrm{C}$ until use.

In the case of cytoplasmic enzymes, pellets were washed with $67 \mathrm{mM}$ potassium phosphate buffer obtained as explained above, and bacteria were resuspended in $1 \mathrm{ml}$ of the same buffer and centrifuged in 2-ml Eppendorf tubes at 8,000 r.p.m. for $10 \mathrm{~min}$ at $4^{\circ} \mathrm{C}$. After carefully removing the supernatant, the cell wet weight was obtained for each pellet in order to calculate the volume of reagents needed for protein extraction using the Novagen BugBuster ${ }^{\mathrm{TM}}$ protocol (EMD Millipore Corp., Billerica, MA, USA). Pellets and cell-free extracts were kept on ice throughout the whole procedure. Bacterial lysis was achieved by adding $5 \mathrm{ml}$ of BugBuster ${ }^{\mathrm{TM}}$ Protein Extraction Reagent per gram of bacterial cell paste. Afterwards, $1 \mu$ l of Lysonase ${ }^{\mathrm{TM}}$ Bioprocessing Reagent was added per $1 \mathrm{ml}$ of BugBuster ${ }^{T M}$ Protein Extraction Reagent used for re-suspension of the cells. Bacteria were lysed by shaking for $20 \mathrm{~min}$ at room temperature in a Rotamax 120 orbital shaker (Heidolph Instruments GmbH \& Co. KG, Schwabach, Germany) at 150 r.p.m. The insoluble cell debris was removed by centrifugation at 13,000 r.p.m. for 20 $\min$ at $4^{\circ} \mathrm{C}$ and the supernatants (i.e. cell-free extracts) were stored at $-20^{\circ} \mathrm{C}$ until use.

In vitro enzymatic assays. In order to determine the activity of two key glycolytic enzymes (Glk and Pfk), the in vitro assays were carried out at $30^{\circ} \mathrm{C}$ when using cell-free extracts from $P$. putida or at $37^{\circ} \mathrm{C}$ when using cell-free extracts from $E$. coli. The remaining activities were measured at $25^{\circ} \mathrm{C}$ as indicated by Sigma-Aldrich Co. (St. Louis, MO, USA) in the corresponding enzymatic assay protocols or by following previously described procedures ( $\mathrm{Ng}$ and Dawes, 1973; Nikel et al., 2014). All the enzymes were assessed under the optimal reported conditions for $\mathrm{pH}$, substrate, and cofactor concentration (Chavarría et al., 2013; Nikel and Chavarría, 2016; Nikel et al., 2014; 2015). In vitro assays were conducted in Nunc ${ }^{\text {TM }}$ MicroWell ${ }^{\text {TM }}$ 96-well microplates (Thermo Fisher Scientific Inc., Waltham, MA, USA) in a SpectraMax ${ }^{\mathrm{TM}}$ M2e multi-mode microplate reader (Molecular Devices LLC, Sunnyvale, CA, USA). All the specific enzyme activities are reported as nmol of substrate converted min $^{-1} \mathrm{mg}$ of protein ${ }^{-1}$. 
Protein concentration in cell-free extracts was assessed using the Bradford Protein Assay (BioRad Laboratories Inc., Hercules, CA, USA) (Bradford, 1976). All the accessory enzymes (with the exceptions indicated below) were from Saccharomyces cerevisiae and they were purchased from Sigma-Aldrich Co. (St. Louis, MO, USA). An extinction coefficient [ENAD(P)/H] of $6.22 \mathrm{mM}^{-1}$ $\mathrm{cm}^{-1}$, representing the difference between the extinction coefficients of $\mathrm{NAD}(\mathrm{P}) \mathrm{H}$ and $\mathrm{NAD}(\mathrm{P})^{+}$. In the case of dichlorophenolindophenol (DCPIP), the extinction coefficients were experimentally determined to be $4.1 \mathrm{mM}^{-1} \mathrm{~cm}^{-1}$ at $600 \mathrm{~nm}(\mathrm{pH}=5.5)$ and $9.1 \mathrm{mM}^{-1} \mathrm{~cm}^{-1}$ at 576 $\mathrm{nm}(\mathrm{pH}=5.5)$. The limit of detection for all the enzymatic assays was consistently below 2-5

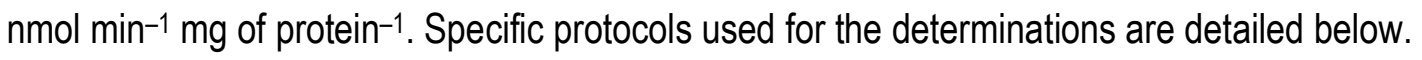

Edd. 6-Phosphogluconate dehydratase (EC 4.2.1.12). The Edd activity was assayed in a two-step reaction protocol by a modification of previously published methods (Baumann and Baumann, 1975; Ponce et al., 2005; Vicente and Cánovas, 1973). The assay mixture contained, in a final volume of $0.1 \mathrm{ml}, 50 \mathrm{mM}$ Tris $\cdot \mathrm{HCl}$ buffer ( $\mathrm{pH}=7.5), 10 \mathrm{mM} \mathrm{MgCl}_{2}, 10 \mu \mathrm{M}$ gluconate- 6 - $P$, and an appropriate dilution of the cell-free extract. This mixture was incubated for $5 \mathrm{~min}$ at room temperature and diluted with the same reaction buffer up to $2 \mathrm{ml}$. The mixture was heated for 2 $\mathrm{min}$ at $95^{\circ} \mathrm{C}$ and centrifuged at 14,000 r.p.m. during $10 \mathrm{~min}$ at room temperature. The supernatant solution was assayed for pyruvate formation by using a mixture that contained 20 $\mu \mathrm{l}$ of the supernatant and $180 \mu \mathrm{l}$ of a solution containing $50 \mathrm{mM}$ Tris $\cdot \mathrm{HCl}$ buffer $(\mathrm{pH}=7.5), 10$ $\mathrm{mM} \mathrm{MgCl} 2,1 \mathrm{mM}$ EDTA, $0.1 \mathrm{mM} \mathrm{NADH}$, and 0.5 units of L-lactate dehydrogenase from bovine heart. The decrease in absorbance at $340 \mathrm{~nm}\left(A_{340}\right)$ was measured during the assay at $37^{\circ} \mathrm{C}$.

Gad. Gluconate 2-dehydrogenase (EC 1.1.99.3). The reaction mixture contained $40 \mu$ of $100 \mathrm{mM}$ sodium acetate buffer ( $\mathrm{pH}=5.5), 16.7 \mu \mathrm{l}$ of $75 \mathrm{mM}$ sodium gluconate, $6.7 \mu \mathrm{l}$ of $15 \mathrm{mM} \mathrm{KCN}$, $33.2 \mu$ l of DCPIP $\left(0.5 \mathrm{mg} \mathrm{ml}^{-1}\right), 96.7 \mu$ of water, and $6.7 \mu$ l of cell-free extract (or an appropriate dilution in $100 \mathrm{mM}$ sodium acetate buffer $\mathrm{pH}=5.5$ ). The decrease in absorbance at $576 \mathrm{~nm}$ $\left(A_{576}\right)$ was measured during the assay.

Gcd. Glucose dehydrogenase (EC 1.1.1.47). The reaction mixture contained $66.7 \mu$ of $100 \mathrm{mM}$ sodium acetate buffer ( $\mathrm{pH}=5.5$ ), $36.7 \mu \mathrm{l}$ of $75 \mathrm{mM}$ glucose, $6.7 \mu \mathrm{l}$ of $15 \mathrm{mM} \mathrm{KCN}, 13.2 \mu \mathrm{l}$ of DCPIP $\left(0.5 \mathrm{mg} \mathrm{ml}^{-1}\right), 70 \mu$ of water, and $6.7 \mu \mathrm{l}$ of cell-free extract (or an appropriate dilution in $100 \mathrm{mM}$ sodium acetate buffer $\mathrm{pH}=5.5)$. The decrease in absorbance at $600 \mathrm{~nm}\left(A_{600}\right)$ was measured during the assay.

Glk. ATP-D-Hexose 6-phosphotransferase or glucokinase (EC 2.7.1.1). The reaction mixture contained $67 \mu$ of $120 \mathrm{mM}$ Tris $\mathrm{HCl}$ buffer ( $\mathrm{pH}=8.2$ ), $26 \mu$ of $500 \mathrm{mM}$ glucose, $8 \mu$ l of $250 \mathrm{mM}$ $\mathrm{MgCl}_{2}, 53 \mu \mathrm{l}$ of $36 \mathrm{mM} \mathrm{ATP}, 10 \mu$ of $20 \mathrm{mM} \mathrm{NADP}^{+}, 13 \mu$ l of glucose-6-P dehydrogenase (15 units $\mathrm{ml}^{-1}$ ), $18 \mu \mathrm{l}$ of water, and $5 \mu \mathrm{l}$ of cell-free extract (or an appropriate dilution in $67 \mathrm{mM}$ potassium phosphate buffer, $\mathrm{pH}=7.1$ ). The increase in $A_{340}$ was measured during the assay. 
Pfk. 6-Phosphofructo-1-kinase (EC 2.7.1.11). The reaction mixture contained $20 \mu$ of $1 \mathrm{M}$ Tris $\cdot \mathrm{HCl}$ buffer ( $\mathrm{pH}=7.5$ ), $2 \mu$ l of $100 \mathrm{mM}$ fructose-6-P, $8 \mu \mathrm{l}$ of $250 \mathrm{mM} \mathrm{MgCl}_{2}, 4 \mu \mathrm{l}$ of $100 \mathrm{mM} \mathrm{NH}_{4} \mathrm{Cl}$, $4 \mu \mathrm{l}$ of $10 \mathrm{mM} \mathrm{NADH}, 6 \mu \mathrm{l}$ of $36 \mathrm{mM} \mathrm{ATP}, 4 \mu$ l fructose-1,6- $P_{2}$ aldolase (50 units ml-1), 1.5 $\mu \mathrm{l}$ of triosephosphate isomerase (500 units $\mathrm{ml}^{-1}$ ), $1.5 \mu$ of glycerol-3-P dehydrogenase from rabbit muscle (170 units $\mathrm{ml}^{-1}$ ), $144 \mu \mathrm{l}$ of water, and $5 \mu$ l of cell-free extract (or an appropriate dilution in $67 \mathrm{mM}$ potassium phosphate buffer, $\mathrm{pH}=7.1$ ). The decrease in $A_{340}$ was measured during the assay. 


\section{SUPPLEMENTARY TABLES}

Table S1. Plasmids used in this study.

\begin{tabular}{|c|c|c|}
\hline Plasmids & Relevant characteristics ${ }^{a}$ & Reference or source \\
\hline pKD46 & $\begin{array}{l}A p^{R} ; \quad \text { helper plasmid expressing the } \lambda \text {-Red } \\
\text { recombination functions }\end{array}$ & $\begin{array}{r}\text { Datsenko and Wanner } \\
(2000)\end{array}$ \\
\hline pCP20 & $\begin{array}{l}\mathrm{Ap}^{R} \mathrm{Cm}^{\mathrm{R}} \text {; helper plasmid used for excision of } F R T \text {-aphA- } \\
F R T\left(\mathrm{Km}^{\mathrm{R}}\right) \text {, Saccharomyces cerevisiae FLP } \lambda c 1857 \lambda P_{R} \\
\operatorname{repA}(\mathrm{Ts})\end{array}$ & $\begin{array}{r}\text { Cherepanov and } \\
\text { Wackernagel (1995) }\end{array}$ \\
\hline pEMG & $\begin{array}{l}\mathrm{Km}^{\mathrm{R}} \text {; oriV(R6K), vector used for deletions, lacZ } \alpha \text { with } \\
\text { two flanking I-Scel target sites }\end{array}$ & $\begin{array}{r}\text { Martínez-García and } \\
\text { de Lorenzo (2011) }\end{array}$ \\
\hline pEMG $\Delta g / k$ & $\begin{array}{l}\mathrm{Km}{ }^{\mathrm{R}} ; \mathrm{pEMG} \text { derivative bearing a } 1.0-\mathrm{kb} \text { TS1-TS2 EcoRI- } \\
\text { BamHI insert for deletion of the glk gene of } P \text {. putida } \\
\text { KT2440 }\end{array}$ & $\begin{array}{r}\text { Sánchez-Pascuala et } \\
\text { al. (2017) }\end{array}$ \\
\hline pEMG $\Delta g c d$ & $\begin{array}{l}\mathrm{Km}{ }^{\mathrm{R}} ; \mathrm{pEMG} \text { derivative bearing a } 1.0-\mathrm{kb} \text { TS1-TS2 EcoRI- } \\
\text { BamHI insert for deletion of the gcd gene of } P \text {. putida } \\
\text { KT2440 }\end{array}$ & This study \\
\hline $\begin{array}{l}\text { pEMG } \triangle \\
P P_{-} 3382-4\end{array}$ & $\begin{array}{l}\mathrm{Km} \text {; } \mathrm{pEMG} \text { derivative bearing a } 1.0-\mathrm{kb} \text { TS1-TS2 EcoRl- } \\
\text { BamHI insert for deletion of the group of genes } \\
\text { PP_3382,PP_3383 and PP_3384 of P. putida KT2440 }\end{array}$ & This study \\
\hline $\begin{array}{l}\text { pEMG } \Delta \\
\text { PP_3623 }\end{array}$ & $\begin{array}{l}\mathrm{Km}{ }^{\mathrm{R}} \text {; pEMG derivative bearing a 1.0-kb TS1-TS2 EcoRI- } \\
\text { BamHI insert for deletion of the PP_3623 gene of } P \text {. } \\
\text { putida KT2440 }\end{array}$ & This study \\
\hline $\begin{array}{l}\text { pEMG } \Delta \\
\text { PP_4232 }\end{array}$ & $\begin{array}{l}\text { Km }{ }^{R} ; \mathrm{pEMG} \text { derivative bearing a 1.0-kb TS1-TS2 Sacl- } \\
\text { BamHI insert for deletion of the PP_4232 gene of } P \text {. } \\
\text { putida KT2440 }\end{array}$ & This study \\
\hline pEMG $\Delta e d d$ & $\begin{array}{l}\mathrm{Km}{ }^{\mathrm{R}} \text {; pEMG derivative bearing a } 1.0-\mathrm{kb} \text { TS1-TS2 EcoRI- } \\
\text { BamHI insert for deletion of the edd gene of } P \text {. putida } \\
\text { KT2440 }\end{array}$ & This study \\
\hline $\begin{array}{c}\mathrm{pEMG} \Delta \mathrm{edd} \\
\Delta g / k\end{array}$ & $\begin{array}{l}\text { KmR; pEMG derivative bearing a 1.0-kb TS1-TS2 EcoRI- } \\
\text { BamHI insert for deletion of the edd gene of } P \text {. putida } \\
\text { KT2440 } \Delta \text { glk }\end{array}$ & This study \\
\hline pSW-| $\left.\right|^{b}$ & $\begin{array}{l}\text { ApR; oriV(RK2), } x y I S, P m \rightarrow I-S c e l \text {, transcriptional fusion } \\
\text { of the gene encoding I-Scel to the } P m \text { promoter }\end{array}$ & $\begin{array}{r}\text { Wong and Mekalanos } \\
(2000)\end{array}$ \\
\hline pSEVA224 & $\begin{array}{l}\mathrm{Km}^{\mathrm{R}} \text {; standard SEVA expression vector, oriV(RK2) } \\
\mathrm{lac} / \mathrm{Q}, P_{\text {trc }}\end{array}$ & $\begin{array}{r}\text { Silva-Rocha et al. } \\
\text { (2013) }\end{array}$ \\
\hline $\mathrm{pS} 224 \cdot \mathrm{GBI}$ & $\begin{array}{l}\mathrm{Km} \text { R; pSEVA224 derivative bearing Module I as an Avrll- } \\
\text { BamHI insert }\end{array}$ & $\begin{array}{r}\text { Sánchez-Pascuala et } \\
\text { al. (2017) }\end{array}$ \\
\hline pPS1 & $\begin{array}{l}\mathrm{Gm}^{\mathrm{R}} \text {; pSEVA441 derivative adapted for easy USER } \\
\text { cloning, oriV(pBBR1), xyIS-Pm }\end{array}$ & Calero et al. (2016) \\
\hline $\begin{array}{l}\text { PSEVA13- } \\
\text { sI3T7-crtEBIY }\end{array}$ & $\begin{array}{l}\text { ApR; oriV }(\mathrm{pBBR} 1), P_{\mathrm{T} 7} \rightarrow \mathrm{crtEB} / \mathrm{Y}, \text { used as a template to } \\
\text { amplify the genes encoding the } \beta \text {-carotene biosynthetic } \\
\text { pathway from Pantoea ananatis }\end{array}$ & Kim et al. (2016) \\
\hline pPS1·CRT & $\mathrm{Gm}^{\mathrm{R}} ; \mathrm{pPS} 1$ derivative, $x y I S, P m \rightarrow \operatorname{crtEB} / Y$ & This study \\
\hline
\end{tabular}

${ }^{a}$ Antibiotic markers: Ap, ampicillin; $\mathrm{Cm}$, chloramphenicol; $\mathrm{Gm}$, gentamicin; and $\mathrm{Km}$, kanamycin. Ts, temperature-sensitive origin of replication.

$b$ This plasmid is the same as pSW(I-Scel) described by Wong and Mekalanos (2000), renamed here as pSW-I for simplicity. 
Table S2. Oligonucleotides used in this study.

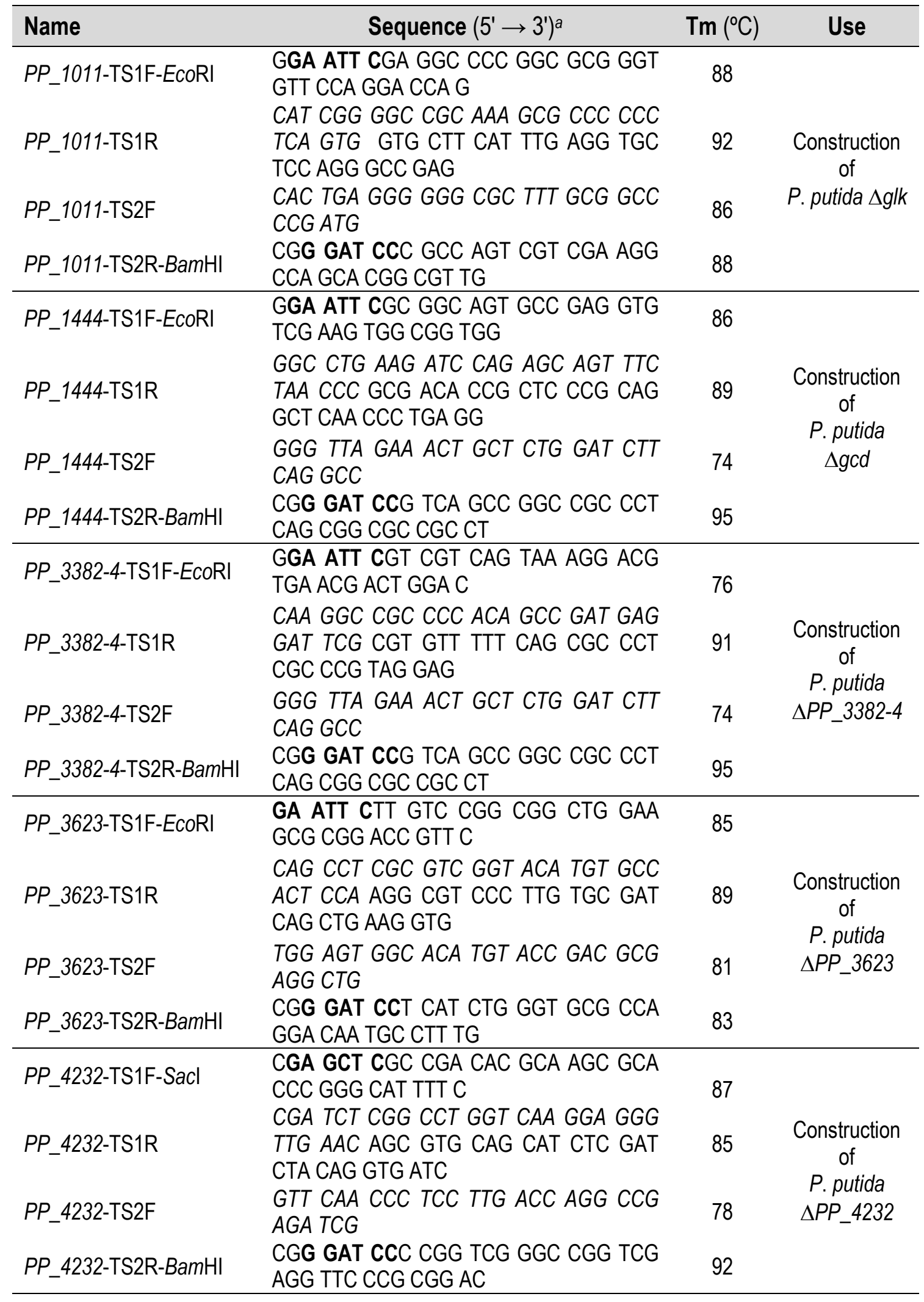




\begin{tabular}{|c|c|c|c|}
\hline PP_1010-TS1F-EcoRI & $\begin{array}{l}\text { GGA ATT CGC ACT GAC CGC GAT ACG } \\
\text { GTC }\end{array}$ & 75 & \multirow{4}{*}{$\begin{array}{c}\text { Construction } \\
\text { of } \\
\text { P. putida } \\
\Delta \text { edd }\end{array}$} \\
\hline PP_1010-TS1R & $\begin{array}{l}\text { CAC CAA CCA GCA GGT GCT TCA TGT } \\
\text { ACT GGA CTC CAG GCT AAT TG }\end{array}$ & 80 & \\
\hline PP_1010-TS2F & \multirow{2}{*}{$\begin{array}{l}\text { ATG AAG CAC CTG CTG GTT GGT G } \\
\text { CGG GAT CCC CTA CCG GCA GGT CAA } \\
\text { CAT G }\end{array}$} & 71 & \\
\hline PP_1010-TS2R-BamHI & & 79 & \\
\hline 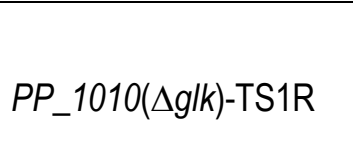 & $\begin{array}{l}\text { GCA AAG CGC CCC CCT CAG TGG TAC } \\
\text { TGG ACT CCA GGC TAA TTG }\end{array}$ & 83 & \multirow{2}{*}{$\begin{array}{c}\text { Used in } \\
\text { combination } \\
\text { with } \\
P P \_1010- \\
\text { TS1F-EcoRI } \\
\text { and } \\
P P \text {-1010- } \\
\text { TS2R-BamHI } \\
\text { to remove } \\
\text { edd in } \\
\text { P. putida } \Delta \text { glk }\end{array}$} \\
\hline$P P_{-} 1010(\Delta g / k)-\mathrm{TS} 2 \mathrm{~F}$ & CAC TGA GGG GGG CGC TTT GC & 75 & \\
\hline pfkA·fbaA-Check-F & GAA AGG TAA AAA ACA CGC GAT C & 59 & \multirow{2}{*}{$\begin{array}{c}\text { Screening of } \\
\text { recombinants } \\
\text { carrying } \\
\text { Module }\left.\right|^{b}\end{array}$} \\
\hline pfkA·fbaA-Check-R & ACG CTG CGA TGG TGA AAC & 59 & \\
\hline crtEB/Y-UC-F & $\begin{array}{l}\text { AAG GAG AUA TAC CTA TGA CGG TCT } \\
\text { GCG }\end{array}$ & 65 & \multirow{4}{*}{$\begin{array}{l}\text { Construction } \\
\text { of plasmid } \\
\text { pPS1.CRT }\end{array}$} \\
\hline crtEBIY-UC-R & $\begin{array}{l}\text { ACG ATG AGU CGT CAT AAT GGC TTG } \\
\text { CAA }\end{array}$ & 67 & \\
\hline pPS1crtEBIY-UC-F & $\begin{array}{l}\text { ACT CAT CGU TAA GAA TTC GAG CTC } \\
\text { GGT ACC CG }\end{array}$ & 69 & \\
\hline pPS1crtEB/Y-UC-R & $\begin{array}{l}\text { ATC TCC TUC CTA GGG CGA TCG CCT } \\
\text { CAG C }\end{array}$ & 71 & \\
\hline
\end{tabular}

a Bold letters indicate recognition site for the restriction enzymes and the complementary sequences used in splicing-by-overlap extension (SOEing) PCR amplifications (Horton, 1995; Nikel and de Lorenzo, 2013) are shown in italics. Oligonucleotides containing $U$ residues, added for USER cloning purposes (Nour-Eldin et al., 2010), are indicated with the identifier 'UC'.

b A PCR amplification using these oligonucleotides yields a 1,015-bp amplicon in the junction of the $p f k A$ and fbaA genes. 


\section{REFERENCES}

Baumann, P., Baumann, L., 1975. Catabolism of D-fructose and D-ribose by Pseudomonas doudoroffi - I. Physiological studies and mutant analysis. Arch. Microbiol. 105, 225-240.

Bradford, M. M., 1976. A rapid and sensitive method for the quantitation of microgram quantities of protein utilizing the principle of protein-dye binding. Anal. Biochem. 72, 248-254.

Calero, P., Jensen, S. I., Nielsen, A. T., 2016. Broad-host-range ProUSER vectors enable fast characterization of inducible promoters and optimization of $p$-coumaric acid production in Pseudomonas putida KT2440. ACS Synth Biol. 5, 741-753.

Chavarría, M., Goñi-Moreno, A., de Lorenzo, V., Nikel, P. I., 2016. A metabolic widget adjusts the phosphoenolpyruvate-dependent fructose influx in Pseudomonas putida. mSystems. 1, e00154-16.

Chavarría, M., Nikel, P. I., Pérez-Pantoja, D., de Lorenzo, V., 2013. The Entner-Doudoroff pathway empowers Pseudomonas putida KT2440 with a high tolerance to oxidative stress. Environ. Microbiol. 15, 1772-1785.

Cherepanov, P. P., Wackernagel, W., 1995. Gene disruption in Escherichia coli: $\mathrm{Tc}^{\mathrm{R}}$ and $\mathrm{Km}^{\mathrm{R}}$ cassettes with the option of Flp-catalyzed excision of the antibiotic-resistance determinant. Gene. 158, 9-14.

Datsenko, K. A., Wanner, B. L., 2000. One-step inactivation of chromosomal genes in Escherichia coli K-12 using PCR products. Proc. Natl. Acad. Sci. USA. 97, 6640-6645.

Horton, R. M., 1995. PCR-mediated recombination and mutagenesis: SOEing together tailor-made genes. Mol. Biotechnol. 3, 93-99.

Kim, S. H., Cavaleiro, A. M., Rennig, M., Nørholm, M. H., 2016. SEVA Linkers: A versatile and automatable DNA backbone exchange standard for Synthetic Biology. ACS Synth. Biol. 5, 1177-1181.

Martínez-García, E., de Lorenzo, V., 2011. Engineering multiple genomic deletions in Gramnegative bacteria: Analysis of the multi-resistant antibiotic profile of Pseudomonas putida KT2440. Environ. Microbiol. 13, 2702-2716.

$\mathrm{Ng}, \mathrm{F}$. M., Dawes, E. A., 1973. Chemostat studies on the regulation of glucose metabolism in Pseudomonas aeruginosa by citrate. Biochem. J. 132, 129-140.

Nikel, P. I., de Lorenzo, V., 2013. Implantation of unmarked regulatory and metabolic modules in Gram-negative bacteria with specialised mini-transposon delivery vectors. J. Biotechnol. $163,143-154$.

Nikel, P. I., Kim, J., de Lorenzo, V., 2014. Metabolic and regulatory rearrangements underlying glycerol metabolism in Pseudomonas putida KT2440. Environ. Microbiol. 16, 239-254.

Nikel, P. I., Chavarría, M., Fuhrer, T., Sauer, U., de Lorenzo, V., 2015. Pseudomonas putida KT2440 strain metabolizes glucose through a cycle formed by enzymes of the EntnerDoudoroff, Embden-Meyerhof-Parnas, and pentose phosphate pathways. J. Biol. Chem. 290, 25920-25932.

Nikel, P. I., Chavarría, M., 2016. Quantitative physiology approaches to understand and optimize reducing power availability in environmental bacteria. In: McGenity, T. J., Timmis, K. N., Nogales-Fernández, B. (Eds.), Hydrocarbon and Lipid Microbiology Protocols - Synthetic and Systems Biology - Tools. Humana Press, Heidelberg, Germany, pp. 39-70.

Nour-Eldin, H. H., Geu-Flores, F., Halkier, B. A., 2010. USER cloning and USER fusion: The ideal cloning techniques for small and big laboratories. Methods Mol. Biol. 643, 185-200.

Ponce, E., García, M., Muñoz, M. E., 2005. Participation of the Entner-Doudoroff pathway in Escherichia coli strains with an inactive phosphotransferase system (PTS- $\mathrm{Glc}^{+}$) in gluconate and glucose batch cultures. Can. J. Microbiol. 51, 975-982. 
Sánchez-Pascuala, A., de Lorenzo, V., Nikel, P. I., 2017. Refactoring the Embden-MeyerhofParnas pathway as a whole of portable GlucoBricks for implantation of glycolytic modules in Gram-negative bacteria. ACS Synth Biol. 6, 793-805.

Silva-Rocha, R., Martínez-García, E., Calles, B., Chavarría, M., Arce-Rodríguez, A., de las Heras, A., Páez-Espino, A. D., Durante-Rodríguez, G., Kim, J., Nikel, P. I., Platero, R., de Lorenzo, V., 2013. The Standard European Vector Architecture (SEVA): A coherent platform for the analysis and deployment of complex prokaryotic phenotypes. Nucleic Acids Res. 41, D666D675.

Vicente, M., Cánovas, J. L., 1973. Glucolysis in Pseudomonas putida: Physiological role of alternative routes from the analysis of defective mutants. J. Bacteriol. 116, 908-914.

Wong, S. M., Mekalanos, J. J., 2000. Genetic footprinting with mariner-based transposition in Pseudomonas aeruginosa. Proc. Natl. Acad. Sci. USA. 97, 10191-10196. 